\title{
Independent Review of Inappropriate Identification, Storage, and Treatment Methods of Polychlorinated Biphenyl Waste Streams
}

Published July 1997

Idaho National Engineering Laboratory Department Lockheed Martin Idaho Technologies Company Idaho Falls, Idaho 83415

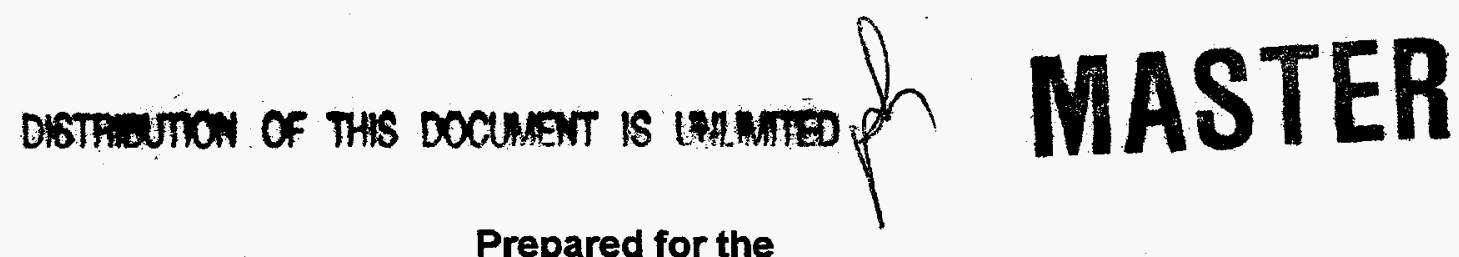
Prepared for the U.S. Department of Energy Under DOE Idaho Operations Office Contract DE-AC07-94ID13223 


\section{DISCLAIMER}

This report was prepared as an account of work sponsored by an agency of the United States Government. Neither the United States Government nor any agency thereof, nor any of their employees, makes any warranty, express or implied, or assumes any legal liability or responsibility for the accuracy, completeness, or usefulness of any information, apparatus, product, or process disclosed, or represents that its use would not infringe privately owned rights. Reference herein to any specific commercial product, process, or service by trade name, trademark, manufacturer, or otherwise does not necessarily constitute or imply its endorsement, recommendation, or favoring by the United States Government or any agency thereof. The views and opinions of authors expressed herein do not necessarily state or reflect those of the United States Government or any agency thereof. 


\section{DISCLAIMER}

Portions of this document may be illegible electronic image products. Images are produced from the best available original document. 


\section{SCOPE OF THE REVIEW}

The Independent Review Team (IRT), which performed this review, was appointed by George E. "Jud" Ellis, Acting Executive Vice President for Operations and Chief Operations Officer, Lockheed Martin Idaho Technologies Company (LMITCO), in a memo dated 4/21/97. Michael Sandvig, Test Area North (TAN) Environment, Safety, and Health Manager, was appointed the lead of the IRT. The team members were selected by Mr. Sandvig. The team members included Leon Horman, Safety and Health, LMITCO; Gordon Venable, Environmental Affairs, LMITCO; Ramona Dunihoo, Environmental Affairs, LMTTCO; Kenneth Vara, Director, B\&W Nuclear Environmental Laboratories; and David Buxbaum, Environmental Compliance Advisor, Lockheed Martin Energy Systems.

The purpose of the review was to evaluate incidents involving the inappropriate identification, storage, and treatment methods associated with polychlorinated biphenyl (PCB) waste streams originating from the V-tank system at TAN. The team was instructed to perform a comprehensive review of LMITCO's compliance programs related to these incidents to assess the adequacy and effectiveness of the management program in all respects including:

- Adequacy of the waste management program in meeting all LMITCO requirements and regulations

- Adequacy of policies, plans, and procedures in addressing and implementing all federal and state requirements and regulations

- Compliance status of LMITCO, LMITCO contract team members, and LMITCO contract/team member subcontractor personnel with established PCB management policies, plans, and procedures.

The V-Tanks are part of an intermediate waste disposal system and are located at the Technical Support Facility (TSF) at TAN at the Idaho National Engineering and Environmental Laboratory (INEEL). The IRT evaluated how a waste was characterized, managed, and information was documented; however, they did not take control of wastes or ensure followup was performed on all waste streams that may have been generated from the V-Tanks. The team has also subsequently learned that the Environmental Restoration (ER) program is revising the plans for the decontamination and decommissioning of the intermediate waste disposal system based on a new information on listed and PCB wastes. The team has not reviewed those in-process changes.

The independent review was conducted using information obtained by interviews of personnel, review of documents, and site visits. The information was evaluated using control analysis, change analysis, and events and causal factor charting. The review was conducted separately from reviews conducted by facility or project personnel. The facility and project personnel conducted reviews for the purpose of implementing corrective actions required to resolve specific operational issues. The other reviewers and the IRT shared information during the initial review of the PCB incidents. 


\section{Report Format}

An Executive Summary follows this section of the report, which provides a brief description of issues and recommendations. Then, the Analysis Section contains the analysis of the relevant facts required to fully describe the weaknesses in the current waste management systems and links to the findings and recommendations found in the Findings and Recommendations Sections of the report. The Findings and Recommendations Sections follow the Analysis Section. The Facts Section at the end of the report details the necessary information needed to support the analysis. The facts contained in this review are many and convoluted. Some of the data in the sections are in story form. This story format was not used in the entire Facts Section, as the effort required to tie all of the information into a story format is not warranted. Information in the Facts Section is supported by interviews or documents and records. The notes from the interviews and copies of the records are included in the IRT files. 
Date: July 9,1997

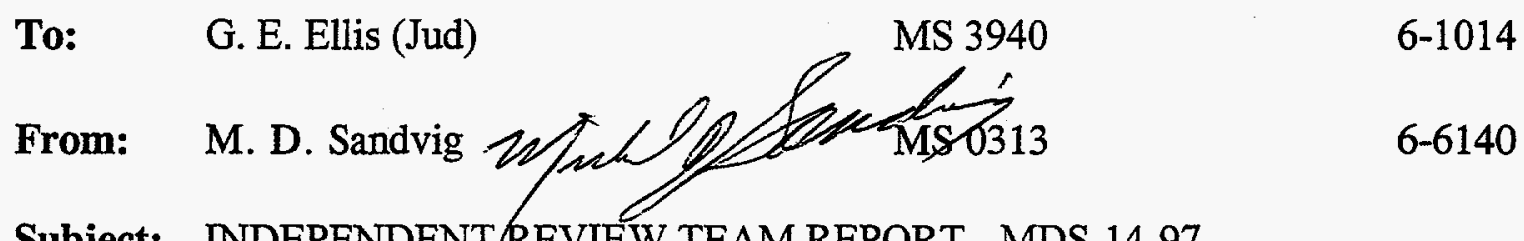

Subject: INDEPENDENT REVIEW TEAM REPORT - MDS-14-97

Attached is the independent review team (IRT) report for incidents involving the inappropriate identification, storage, and treatment methods of polychlorinated biphenyl waste streams.

The report is long and detailed; however, the report does reflect the true complexity of the waste management issues. An executive summary has been provided for a brief description of issues and recommendations to aid in a quick understanding of the problem. Then, the analysis section contains the evaluation of the facts required to fully describe the weaknesses in the current waste management systems. The analysis section also provides the links to the findings and recommendations. The finding and recommendation sections follows the analysis. The fact section, at the end of the report details the necessary information needed to support the analysis. Although the facts contained in this review are many and convoluted, some of the data in the section are in story form. This story format was not used in the entire fact section, as the effort required to tie all of the information into a story format is not warranted. Information in the fact section is supported by interviews or documents and records. The notes from the interviews and copies of the records are included in the IRT files.

The review team did not perform a follow-up on any waste not associated with the V-Tank system that is located at Test Area North. The review team evaluated how a waste was characterized, how it was managed, and how information was documented. The review team did not take control of wastes or ensure follow-up was performed on all waste streams that may have been generated from the V-Tanks. The team has determined that the Environmental Restoration (ER) personnel are revising the plans for the decontamination and decommissioning of the intermediate waste system based on the new information on listed and PCB wastes. The team has not reviewed those in-process changes.

If you have any questions, please do not hesitate to call.

jd

Attachment 


\section{EXECUTIVE SUMMARY}

An intermediate radioactive waste system was put into operation in the 1950 s to support the Aircraft Nuclear Propulsion (ANP) project at Test Area North (TAN) at the Idaho National Engineering and Environmental Laboratory (INEEL). (See Appendix A). This system is referred to as the Intermediate Level Waste Disposal System (ILWDS) or the V-Tank system. The V-Tank system was later used to support general TAN Hot Shop Operations, including the Loss-of-Fluid Test (LOFT) project, from 1965 until 1985. The system is an interconnected system and consists of holding tanks, a valve pit, and an evaporator. The system handled radioactive liquids, decontamination solutions, and degreasing agents which contained trichloroethylene, and tetrachlorethene. The effluent from the system originally discharged to an injection well or at times to a surface pond. The effluent was hauled in a tanker truck to the Idaho Chemical Processing Plant (ICPP) beginning in 1975 .

Oil was discovered in one of the tanks in 1968 and 60 gallons were subsequently removed in 1981. The oil was found to have PCB contamination at a concentraiton of $680 \mathrm{ppm}$ in approximately 1980-1981. Waste flows to and from the V-Tanks are shown in Figure 1. Subsequent analysis of liquids, sludges, and concrete cores of other components of the V-Tank system have shown PCBs at concentration of $\geq 50 \mathrm{ppm}$ the level of PCBs regulated under the Toxic Substances Control Act (TSCA). The tanks and the system have never been managed under TSCA or the Resource Conservation and Recovery Act (RCRA). The waste system has been inactive since 1985 and is currently being addressed by LMITCO ER Program under the Comprehensive Environmental Response, Compensation, and Liability Act (CERCLA) through the Federal Facilities Agreement/Consent Order (FFA/CO).

A sampling event was conducted in 1993 by EG\&G Idaho's ER organization on the V-tanks to characterize the waste. Samples were taken from the aqueous liquid and sludge phases. A PCB analysis was requested for the 1993 samples; however, the analysis was not performed as the laboratory lacked this capability. Though PCBs were suspected, the personal protective equipment (PPE) used during the sampling event was not managed as potentially PCB-contaminated materials or as mixed waste but only as low-level radioactive waste (LLW). The approximately 8 cubic feet of potentially PCBcontaminated waste is believed to be intermingled with up to 15 cargo containers of LLW. Its identity as potentially PCB-contaminated waste was lost when it was sorted for incineration or compaction with other LLRW from TAN. The sample and analysis residues were also not managed as PCB waste. Some of the sample residues were discharged into a process equipment waste (PEW) system at the ICPP that is not approved for TSCA waste. Other residues were stored in an accumulation area due to the high chloride incompatibility with the PEW. This material was shipped to and incinerated at the Waste Experimental Reduction Facility (WERF) in 1996. The WERF incinerator is not permitted to burn PCB material $>5$ ppm or any TSCA-regulated material. The ash from this WERF burn is currently in storage awaiting disposition.

In 1996, ER (LMITCO) again sampled the aqueous and sludge phase of the V-Tanks for further characterization. The PPE from this sampling event also was not managed as potentially PCB-contaminated or as mixed waste. As with the 1993 PPE, this 
PPE also lost its identity after it was intermingled with other LLW at TAN. The samples from the 1996 event were analyzed for PCB contamination at the Remote Analytical Laboratory (RAL) at the ICPP, and at an off-site commercial nuclear environmental laboratory. All of the 1996 samples and residues were handled as potentially PCBcontaminated material except sample residues from two samples at the RAL (a 1-gram sample and a 1.5-gram sample). Residues from these two samples were discharged into the ICPP PEW system. Analysis results from the aqueous liquids were all well below $<50$ $\mathrm{ppm}$ PCB. Analysis results from the sludge in the tanks ranged from $<1 \mathrm{ppm}$ to $660 \mathrm{ppm}$ PCB. Sludge material from all of the tanks sampled during this sampling event, except one, tested $>50 \mathrm{ppm}$ PCB. Therefore, those materials that come in contact with this waste, samples, and sample residues all should have been managed in accordance with the TSCA regulations.

The direct cause of these events was failure to apply known RCRA characterization information and concentrations of PCB levels to waste in the TAN V-Tank system, and to communicate this information to those with a need to know. This failure directly affected subsequent management, storage, and disposal of several waste streams generated during sampling and analysis events. The level of knowledge of some individuals associated with the characterization also played a factor in this direct cause, including a lack of understanding as to how the various in contact rules apply to waste regulated by TSCA as well as RCRA. The root cause of these events is the failure to properly close the tanks and manage the waste that remained in the system at the time of deactivation in 1986.

Since 1996, the level of compliance by the U.S. Department of Energy (DOE) and its contractors, with the applicable environmental laws and regulations has increased. Therefore, the root cause of the event should not be a significant factor for current operations, though the direct cause and its contributing causes need to be addressed. 
PCB Waste Flow To and From TAN V-Tanks

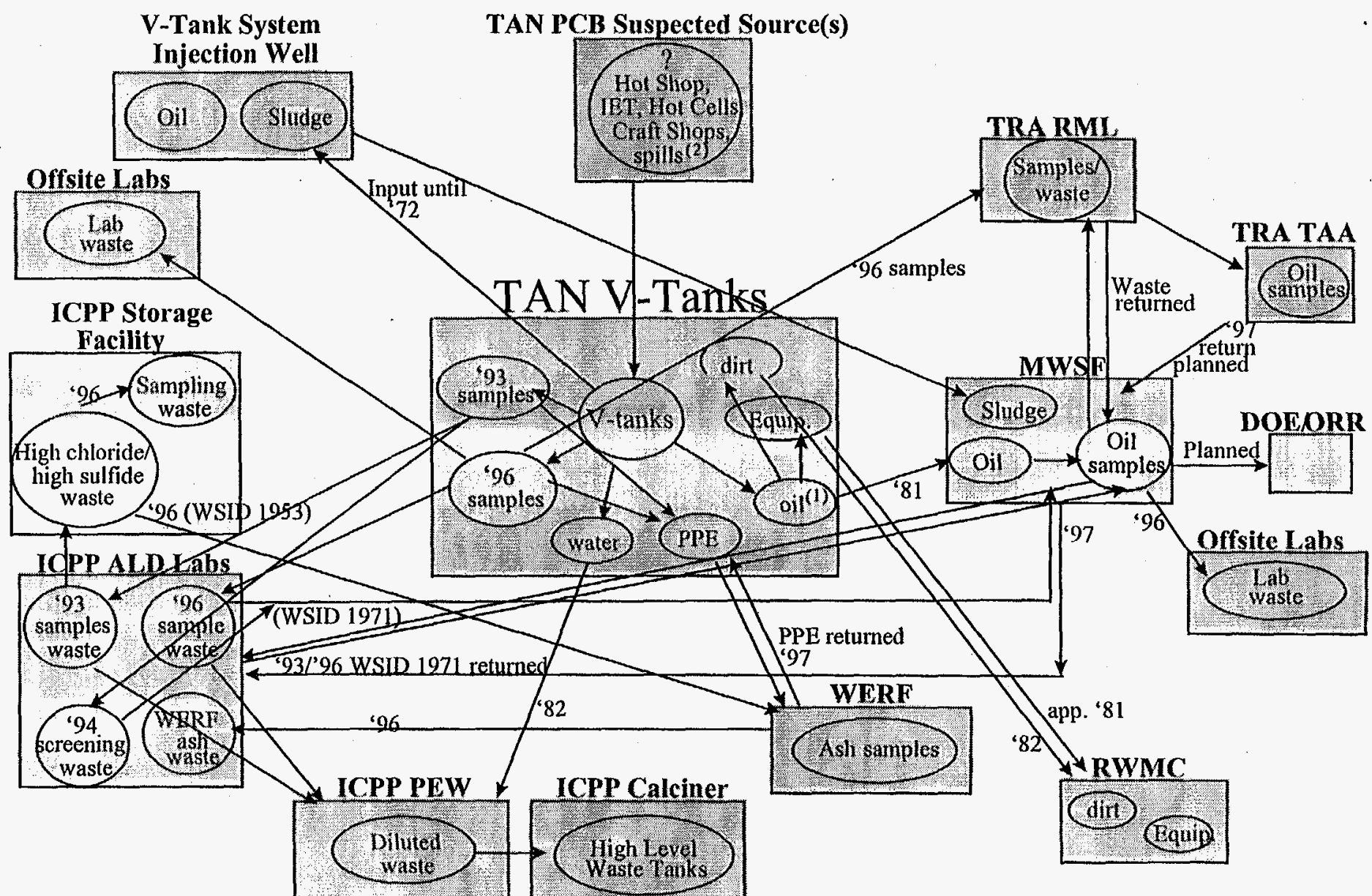

(1) Original source of PCBs in V-tank system suspected to be a spill of hydraulic fluid in '68

(2) Spills prior to 2/17/78 (effective date of TSCA)

Figure 1. PCB waste flow to and from TAN V-Tanks. 


\section{CONTENTS}

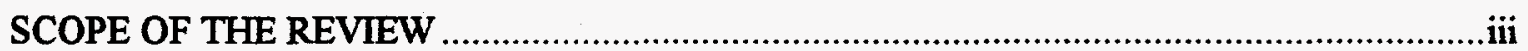

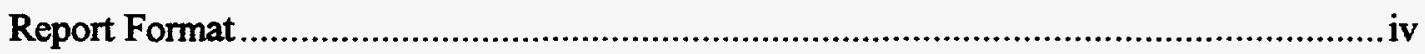

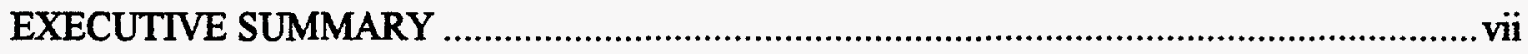

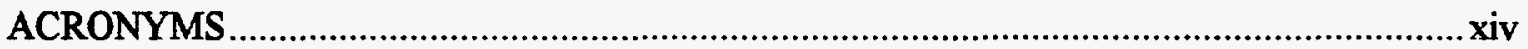

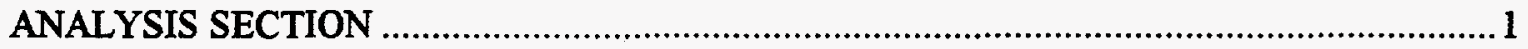

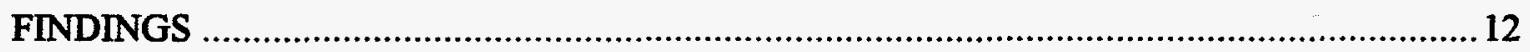

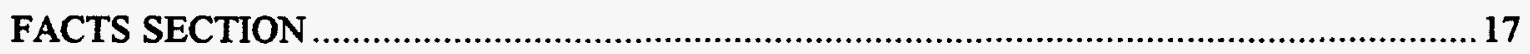

About PCBs (Polychlorinated Biphenyls) ................................................... 17

Characterizing Waste.............................................................................. 17

Hazardous Waste Defined............................................................................... 18

Hazardous Waste Generation ........................................................................... 18

Technical Support Facility Intermediate-Level Waste Disposal System

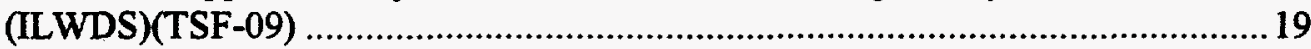

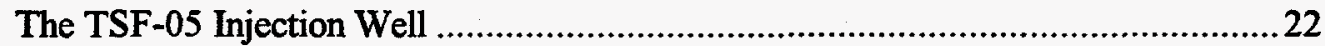

TAN V-Tank Operation History Including Waste Management ............................. 23

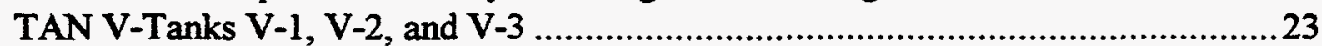

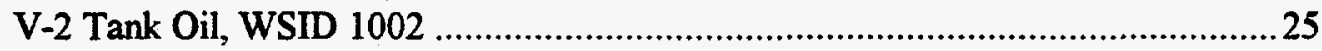

1993 V-Tank Sampling and Analysis Scenario Including Waste Management.........27

RAL High Chloride Waste, WSID 1953 ..........................................................22

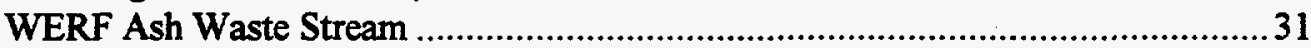

1996 V-Tank Sampling and Analysis Scenario Including Waste Management..........32

V-Tank Analytical Wastes WSID 1971.............................................................35

Other PCB Characterization and Waste Management Issues Identified ...................37

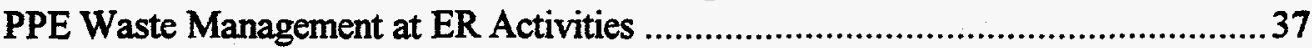

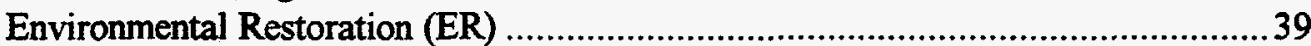

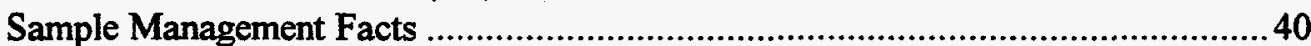

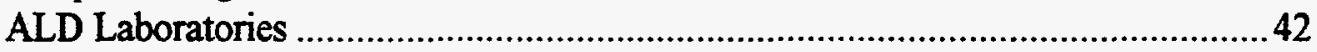

Laboratory Handling of V-Tank Samples and Waste ........................................44

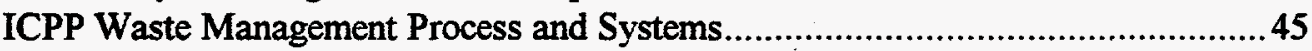

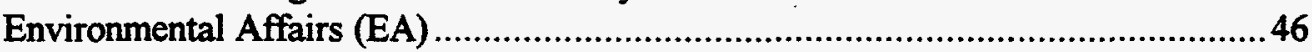

Characterization of Wastes at LMITCO-Managed INEEL Facilities......................48

Waste Reduction Operation Complex (WROC) ..............................................50

Appendix A-Brief History of Evolution of the Department of Energy 


\section{FIGURES}

1. PCB waste flow to and from TAN V-Tanks........................................

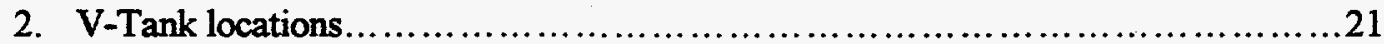

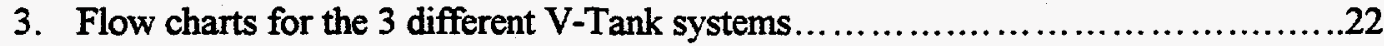

4. Intermediate-level waste collection system................................. 47 


\section{ACRONYMS}

AEA Atomic Energy Act

AEC Atomic Energy Commission

AEDL Applied Engineering Developmental Laboratory

ALD Analytical Laboratory Department

ANL-W Argonne National Laboratory West

ANP Aircraft Nuclear Propulsion (project)

ARA Army (Auxiliary) Reactor Area

ATR Advanced Test Reactor

B\&W Babcock and Wilcox

CERCLA Comprehensive Environmental Response, Compensation, and Liability Act

CFA Central Facilities Area

CFR Code of Federal Regulations

CHP Chemical Hygiene Plan

COCA Consent Order and Compliance Agreement

D\&D Decontamination and Decommissioning

DCE Dichloroethylene

DEQ (Idaho) Department of Environmental Quality

DOE Department of Energy

EA Environmental Affairs

EBR Experimental Breeder Reactor

ECU Environmental Chemistry Unit

EPA Environmental Protection Agency

ER Environmental Restoration 


\begin{tabular}{|c|c|}
\hline ERDA & Energy Research and Development Administration \\
\hline ERRC & Environmental Restoration Review Committee \\
\hline ES\&H & Environmental, Safety, and Health \\
\hline ETU & Environmental Technology Unit \\
\hline FFA/CO & Federal Facilities Agreement/Consent Order \\
\hline FFCA & Federal Facility Compliance Act \\
\hline GWTF & Groundwater Treatment Facility \\
\hline ICPP & Idaho Chemical Processing Plant \\
\hline IDW & Investigation-Derived Waste \\
\hline IET & Initial Engine Test \\
\hline IH & Industrial Hygiene \\
\hline ILWDS & Intermediate Level Waste Disposal System \\
\hline INEEL & Idaho National Engineering and Environmental Laboratory \\
\hline NEL & Idaho National Engineering Laboratory \\
\hline IRC & INEEL Research Center \\
\hline IRT & Independent Review Team \\
\hline LDR & Land Disposal Restrictions \\
\hline LEAF & Legal Environmental Assistance Foundation \\
\hline LIMS & Laboratory Information Management System \\
\hline LLRW & Low-Level Radioactive Waste \\
\hline LMITCO & Lockheed Martin Idaho Technologies Company \\
\hline LOFT & Loss-of-Fluid Test (Reactor) \\
\hline MCP & Management Control Procedure \\
\hline MLLW & Mixed Low-Level Waste \\
\hline MWSF & Mixed Waste Storage Facility \\
\hline
\end{tabular}




\begin{tabular}{|c|c|}
\hline NRC & Nuclear Regulatory Commission \\
\hline NRF & Naval Reactors Facility \\
\hline NRTS & National Reactor Testing Station \\
\hline NWCF & New Waste Calcining Facility \\
\hline oOs & Out of Service \\
\hline ORNL & Oak Ridge National Laboratory \\
\hline ORPS & Occurrence Reporting and Processing System \\
\hline OSHA & Occupational Safety and Health Administration \\
\hline OU & Operable Unit \\
\hline PCB & polychlorinated biphenyl \\
\hline PCE & $\begin{array}{l}\text { Tetrachloroethene (more commonly known as parchloroethylene or } \\
\text { tetrachloroethylene }\end{array}$ \\
\hline PEW & Process Equipment Waste \\
\hline PO & Project Office \\
\hline POC & point of contact \\
\hline PPE & personal protective equipment \\
\hline PPM & parts per million \\
\hline PRD & Program Requirements Document \\
\hline RAL & Remote Analytical Laboratory \\
\hline RCRA & Resource Conservation and Recovery Act \\
\hline RI/FS & Remedial Investigation/Feasibility Study \\
\hline RML & Radiation Measurements Laboratory \\
\hline ROD & Record of Decision \\
\hline RPSSA & Radioactive Parts and Service Storage Area \\
\hline RRWAC & Reusable Property and Recyclable Materials Waste Acceptance C \\
\hline
\end{tabular}


RWMC Radioactive Waste Management Complex

RWMIS Radioactive Waste Management Information System

SAA Satellite Accumulation Area

SAP Sampling and Analysis Plan

SARA Superfund Amendments and Reauthorization Act

SMC Specific Manufacturing Capability

SME Subject Matter Expert

SMO Sample Management Office

SOW Statement of Work

SPERT Special Power Excursion Reactor Test

SWEPP Stored Waste Examination Pilot Plant

TAA Temporary Accumulation Area

TAN Test Area North

TANO Test Area North Operations

TCE Trichloroethylene

TCLP Toxicity Characteristic Leaching Procedure

TOS Task Order Statement

TRA Test Reactor Area

TSCA Toxic Substances Control Act

TSD Treatment, Storage, and Disposal

TSF Technical Support Facility

TWCP Transuranic Waste Characterization Project

USGS United States Geological Survey

WAC Waste Acceptance Criteria

WAG Waste Area Group 


$\begin{array}{ll}\text { WAP } & \text { Waste Analysis Plan } \\ \text { WERF } & \text { Waste Experimental Reduction Facility } \\ \text { WGI } & \text { Waste Generator Interface } \\ \text { WINCO } & \text { Westinghouse Idaho Nuclear Company } \\ \text { WIPP } & \text { Waste Isolation Pilot Plant } \\ \text { WMA } & \text { Waste Management Authority } \\ \text { WO } & \text { Waste Operations } \\ \text { WROC } & \text { Waste Reduction Operations Complex } \\ \text { WSID } & \text { Waste Stream Identification (number) }\end{array}$




\section{ANALYSIS SECTION}

\section{V-Tank Process Knowledge}

Management responsibility for the tanks and waste associated with the V-Tanks has changed numerous times over the past 16 years. The materials in the V-Tanks have been evaluated several times over the tanks' history, and the available process knowledge has been used to characterize the waste. Process knowledge and information regarding stored wastes taken from those tanks is diminishing due to attrition and reductions in work force.

The 1995 Record of Decision (ROD) for the Technical Support Facility (TSF) Injection Well, which is at the end of the V-Tank system, stated an insufficient knowledge existed in how the TCE found in the groundwater was used at TAN. Based on this lack of knowledge, the ROD declared the TCE waste, RCRA characteristic waste only. The recent sampling and other analysis performed on the TSF-21 Valve Pit, which is in the front end of the V-Tank system, resulted in a hazardous waste determination that it contained RCRA "F-listed" waste.

The V-Tanks are known to have contained PCBs since the oil was removed from the V-2 Tank in 1981. The hazardous waste manifests associated with shipping this material noted a PCB contamination level of $680 \mathrm{ppm}$. Other documents also reference this value. The original sample analysis documentation for the oil has not been located. However, the $680 \mathrm{ppm}$ concentration is reasonable based on the results of the 1996 sample analysis, which indicated a PCB concentration of $660 \mathrm{ppm}$ in the sludges. Although the V-2 Tank was known to have contained PCBs, neither it or any other part of the system has ever been regulated under TSCA. The TSCA regulations require wastes contaminated with $\mathrm{PCBs} \geq 50 \mathrm{ppm}$ to be managed and disposed by approved methods. The TSCA regulations may also regulate waste contaminated with $\mathrm{PCBs}<50 \mathrm{ppm}$ if it has come in contact with $\mathrm{PCBs} \geq 50 \mathrm{ppm}$. Because of the antidilution provision, secondary wastes that have been in contact or mixed with PCB wastes $\geq 50 \mathrm{ppm}$ become TSCA regulated, even if PCBs are not detectable in the secondary waste.

Knowledge of PCB contamination in the supernatant and sludges was very important to the characterization of the V-Tank waste streams. The 1993 sample materials were not controlled as PCB wastes. The PPE generated in the 1996 sampling event was not controlled as PCB waste. ER records generated in the initial CERCLA analysis of these tanks and other CERCLA sites state there are PCBs in the V-2 Tank at $680 \mathrm{ppm}$ (reference 1986 Informal Report EGG-WM-6875). The ER personnel involved in the sampling events stated they did not
Finding 1 - Several cognizant and responsible organizations did not properly manage $\mathrm{PCB}$ wastes found in the $V$ Tank system at (or from) TAN.

F1(a) Past contractors failed to document in records their process knowledge of waste discharged to the V-Tank systems.

See Recommendations la, $1 b$, and 7.

F1(b) Past contractor failed to maintain in a retrievable format documentation related to the waste characterization of V-Tank wastes.

See Recommendation $1 \mathrm{~b}$.

F1(c) PPE wastes were not managed as PCB waste per TSCA.

See Recommendation la.

Finding 2 - Personnel characterizing waste are not always adequately skilled, trained, experienced, and supervised. 
expect the PCB levels to be at $50 \mathrm{ppm}$, nor did they realize that PCB concentrations associated with oils removed 16 years ago would apply to tanks for which they were now responsible. Several said they did not know what "TSCA regulated" means or how it is triggered.
F2(a) The ER personnel did not recognize the potential for PCBs to migrate from the oil into the other waste components within the V-Tanks.

See Recommendations le and 2.

F1(d) The tanks were not operated under adequate regulation.

This issue is now resolved due to the DOE acceptance of external regulation by the Environmental Protection Agency EPA and agreement with State agencies. No recommendation is required for this finding.

F2(b) The current company systems do not specify the minimum qualifications required to certify characterization of wastes.

See Recommendation le. 
important to have at least one qualified person perform a review of all characterizations. It is not possible or wise to certify everyone in the process. At times a chemist, waste handler, generator, engineer, or other persons with knowledge may be brought into the process. These persons may provide only specialized information or operations information, therefore, qualifying everyone is not required.

\section{Waste Management Roles and Responsibilities}

The responsibility for a waste and its characterization may be handed off several times in the process of analysis, management, treatment, and disposal. The roles and responsibilities of each of the "handlers" in the process is not well-defined. The process a waste stream goes through depends on the facility it is handled at or will be handled at. It also depends on what treatment is prescribed for the waste. At the ICPP, a generator submits a request to create a waste stream to the ICPP Waste Management Authority (WMA). The WMA reviews data for material composition, origin, process knowledge, associated listed and characteristic waste codes, and proposed disposal routes and determines if it is compatible with existing waste streams and designates how the waste is to be handled. The WMA depends heavily on the knowledge of the generator. The ICPP generator may be a secondary generator if the material was already a waste before it was brought into the facility.

The ICPP WMA process in general appears to have been effective in the past when dealing with ICPP-related waste instead of unrelated wastes being brought into the ICPP system. The process of characterization of the latter wastes can be tedious. First, the data are reviewed by a committee. If the data are inadequate or incomplete, then the generator may be responsible to resubmit the request to the WMA. This lengthens the time to get a waste stream approved greatly. If the generator is one of the laboratories at the ICPP, they may not know anything about the waste other than what the sampler provides (except for how the analysis method changes the waste). In the case of Environmental Management-funded work, the sampler currently furnishes the Sample Management Office (SMO) with the characterization data, then the SMO provides the data to the laboratory point of contact (POC). The primary generator or sampler does not attend the ICPP WMA meeting; only the laboratory POC attends. If the sampler's data are incomplete, the laboratory POC is expected to resolve the issue. In some cases, the samples have already been taken and await analysis and thus the holding times can be exceeded. After the laboratory is finished analyzing, the POC must work with Waste Reduction Operations Complex (WROC) Waste Generator Interface (WGI) to get the waste disposed. The WGIs may ask for more information and may not agree with the earlier characterization made by the WMA. Again, the POC is the middle man between the original generator and the WGI. The process
F1(e) The generator does not always provide adequate information or documentation to perform an adequate characterization of waste.

See Recommendations 1a, $\mathrm{lb}$, and 2. 
to perform the characterization should not be based on committee work alone, and must be streamlined. That does not mean characterization should be done by one person. Each stream should be evaluated with those persons needed to accomplish the task.

Generators submitting samples must be involved in the

characterization process instead of being left out of the process.

\section{Waste Storage, Treatment, and Disposal}

The current role of the WMA at ICPP, Test Reactor Area (TRA), and TAN ends when the waste stream is approved. The generator then works with Waste Operations (WO) on a disposal path. The WMA process at ICPP does not require that the WMA board members communicate with WO. Even if the waste is fully characterized from the WMA perspective, the job may not be done unless the waste and waste characterization information meets the needs of the treatment and disposal facility. These facilities may have Waste Acceptance Criteria (WAC) that limit the concentrations of certain materials. At other times the receiving disposal facilities may have operational needs that cause them to want to know more about a waste so they can better fit it into a treatment and/or disposal method. The IRT found the WGI personnel have frequently requested additional data and additional sampling for characterization after a waste has been fully R.CRA characterized. This is an indication of the low level of confidence in the existing data from the generator. Interviews with WMA and WGI personnel confirmed such practices in characterizing wastes for treatment or disposal.

The V.Tank system is one of many inactive systems at the INEEL that were abandoned in place. The wastes from these systems are called "legacy wastes." The potential for inaccurate characterization due to incomplete process knowledge continues to exist. In addition to the importance in characterizing legacy waste, detailed information regarding how that characterization is accomplished should follow the material. Supplying only the waste codes on the documents can lead to second guessing by others as to the basis of the characterization. Such second guessing degrades the confidence in the process as a whole. A system of passing on characterization data and its basis must be established.

\section{Communication of New Information Regarding Waste}

Often new information regarding waste characterization associated with wastes still stored at the INEEL does not appear to be passed on. The IRT noted that in general when new information becomes available that impacts waste already shipped to storage and/or disposal facilities, generators would not track all of those wastes down and notify the facilities to add newly identified codes. Wastes shipped from ICPP and burned at WERF did not carry the proper
F1(e) The generator does not always provide adequate information or documentation to perform an adequate characterization.

See Recommendations la, $1 b$, and 2.

F1(f) The generators did not apply the new characterization data to wastes still in the INEEL on-site system. 
waste codes because the ICPP laboratories were unaware of additional waste characterization information.

A number of waste streams generated from the V-Tanks still exist at the ICPP, WROC, TRA, and TAN, some of which are not properly characterized.

- The cargo containers returned from WERF, now stored at the TAN Radioactive Parts and Service Storage Area (RPSSA), contain a small amount of potentially PCB-contaminated PPE from V-Tank sampling activities and are co-mingled with other low-level radioactive waste (LLW).

- All of the co-mingled waste could be viewed as PCB listed-mixed waste. Disposal of all of this waste as PCB listed-mixed will be significantly more expensive than it would have been to manage the waste had it been segregated. Had the knowledge that these wastes were PCB contaminated and listed been known by TAN Operations personnel, they could have segregated it from the LLW. This segregation method would have kept the PCB listedmixed waste volume to a minimum.

- Another waste from the V-Tank system currently in the INEEL system should have had " $F$ " codes assigned to it when it was determined that "F" codes applied to the V-Tank system. This waste is the 60 gallons of V-2 Tank oil. The oil is stored at the Mixed Waste Storage Facility (MWSF). WROC has planned to ship this waste to the DOE Oak Ridge Reservation TSCA incinerator for disposal.

- Personnel at the ICPP have been trying to reconcile the waste code differences on the waste in their system for some time. They have various streams of sampling analysis waste from the $V$-Tank system and have noticed the new waste codes missing on related waste streams sent to the RAL for analysis from WROC.

The existing waste stream information system and processes are not designed to allow efficient tracking of INEEL waste and for the changing of waste codes by the original generator or the current manager of the waste source. Therefore, the current managers of the waste source will have a difficult task locating all of the existing V-Tank wastes still circulating through the INEEL's waste management system.
Finding 4 - Samples taken of TAN V-Tank system wastes and resulting analysis wastes have not been managed as known or suspected PCB-contaminated materials due to improper characterization.

See Recommendations 1b, $1 c$, and 2.

F1(g) The ability to track current locations of waste is limited to manual searches of all waste records.

See Recommendation 1c. 
According to documents reviewed during this assessment, the PCB contaninated oil was discovered in the V-2 Tank in 1968. The Intermediate Level Waste Disposal System (ILWDS) discharged to the TSF-05 Injection Well. The operation of the TSF-05 Injection Well continued until 1972. The CERCLA Remedial Investigation Final Report with Addenda for the Test Area North Groundwater Operable Unit 1-07B at the Idaho National Engineering Laboratory, Volume 1, EGG-ER-10643, January 1994, is the technical basis for the ROD 1-07B. The report included recorded PCB sample analysis results for ground and not the sludges. The report does not evaluate the risk for PCB contamination in the groundwater. Recent samples have detected only 2-7 ppb of PCB contamination. While this indicates a low risk from PCB contamination, a full technical, risk and regulatory evaluation should be conducted. This evaluation would determine if modifications are necessary to the ROD. Records indicate that wastes which may contain sludges removed from the injection well are still in storage in the MWSF. Analysis of the sludges removed from the injection well for PCBs can help determine if it should be a contaminant of concern.

\section{Waste Management of Samples and Sample Waste}

The Sampling and Analysis Plan (SAP) writer should have good characterization information based on process knowledge and that information must be passed on to those handling the samples. As stated earlier, many of the samples are from systems that have legacy wastes. The samples may be taken to characterize the waste; therefore, there are unknowns associated with the waste. In this scenario, special handling is required, and wastes should accumulate until the characterization is completed by the laboratory. Special instructions on the handling methods must be communicated to the laboratories. This was not adequate in the 1993 and 1996 sampling events. The fact that PCB contamination may be present in the samples was not communicated to the ICPP WMA. Although the personnel believed the contamination levels would be below $50 \mathrm{ppm}$, they did not consider the impact of the TSCA antidilution provision and the WAC of the receiving facility. The ICPP is attempting to keep all PCB waste out of the PEW, so they needed to know there were PCBs in the 1993 samples. The WAC at WERF requires PCB levels to be less than $5 \mathrm{ppm}$, so ICPP needed to know the levels so they could pass on the information to WERF.

Characterization can be complicated. It was discovered that WROC attempts to have wastes that are generated during analysis segregated based on the current PCB concentrations after analysis versus the greatest PCB concentration with which the waste came in contact. It was also discovered that information communicated by the SMO
F1(h) The 1-07B

Remedial Investigation/ Feasibility Study (RI/FS) did not contain a technical and risk evaluation for PCB contamination.

F1(i) The internal reviews of the RI/FS did not correct the lack of a PCB evaluation.

See Recommendations 2 and 3.

F1(e) The generators do not always provide adequate information or documentation to perform an adequate characterization of waste.

F2(a) The ER personnel did not recognize the potential for PCBs to migrate from the oil into the other waste components within the tanks.

Finding 3 Characterization information has not been 
about a waste is based on the type of analysis performed. If a radiation only analysis is ordered, only radiation data are communicated. Some radiological analysis methods require a chemical extraction to be performed, thus a mixed waste may be created. If the sample is PCB contaminated, that contamination or its concentration level information is not communicated. The characterization will not be correct if the laboratory does not have full disclosure by the generator. The laboratory is also expected to anticipate what contaminants are in the wastes based on the requested analysis. As discussed previously, a material could be regulated by the contact rule, therefore, samples may be regulated regardless of analysis results. In the end, the disposal of the samples is not likely to be correct if the other hazardous characteristics are unknown to the laboratory. The current system does not relay new characterization data to other affected parties as unknown samples are analyzed so analysis wastes can be properly managed. This communication must be established for all laboratories, both on-Site and off-Site.
ICPP procedures state that generation of a waste stream (thus analysis) may not begin until generators [the Analytical Laboratory Department (ALD)] have an approved WMA, unless it is an "emergency" as defined by their procedure, WN-23, Waste Stream Approval Process. However, the WMA allowed the ALD laboratories to analyze samples before a full approval to meet ER needs. The current WMA Coordinator indicated during interviews that this exception to the rules, allowing for analysis before full approval through disposal, may actually be a common practice with environmental samples now analyzed at ICPP. applied in a consistent manner in accordance with the regulations.

F3(a) The in contact rule in TSCA prohibits dilution of PCB contamination as a method to seek relief from disposal requirements.

Finding 4 - Samples taken of TAN V-Tank system wastes and resulting analysis wastes have not been managed as known or suspected PCBcontaminated materials due to improper characterization.

Finding 5 - The SMO Task Order Statements (TOSs) do not always provide all known or suspected hazardous constituent information to laboratories analyzing INEEL samples.

Finding 8 - On-Site and off-Site laboratories are not notified of additional waste characterization information, identified after samples have been sent to those laboratories, to ensure proper management of analysis wastes.

See Recommendations la, $1 \mathrm{~b}, 1 \mathrm{~d}, 1 \mathrm{e}, 2$, and 4. 
The WMA never granted final approval for the disposal of the VTank analysis wastes from the 1996 sampling event. The laboratory was granted approval to analyze; they were not granted approval to dispose of the waste. They were directed to hold the waste until the disposal path was approved by the WMA. All of the ICPP laboratory sample wastes for the 1996 sampling event, except for two small samples, were correctly collected. The two small samples were disposed of down the drains that eventually go to the PEW. This practice was in direct violation of procedure, WN-23, Waste Stream Approval Process, and the written instruction provided by the WMA. The laboratory POC specifically authorized the chemist to dispose of the two 1996 sample wastes in the drain that eventually goes to the PEW. He stated that he believed the analytical method, a lithium borate fusion analysis, would destroy all organics, including PCBs. This practice violated LMITCO's conduct of operations principles and TSCA regulations even if the analytical method destroyed the PCBs.

\section{Capability of Handling "Environmental" Samples on Demand at ALD}

The ICPP and TRA laboratories of the ALD are currently facing two major issues that directly affect their ability to respond rapidly to unscheduled or "on-demand" analysis requests from site customers. The first is the waste management requirements for characterization data on the sample, and the second is the budgeting and staffing mechanism for the laboratory.

In an effort to avoid regulatory noncompliance for handling wastes, several procedures have been established for obtaining and communicating information about samples. These procedures require the generator of the sample to disclose all relevant information about known or suspected wastes in that sample. Evaluations of this information are performed, usually in a committee format, so that appropriate disposal options are identified. This up-front planning process is designed to facilitate the disposal of samples at the conclusion of the analysis, before the expiration of any regulatory deadlines. While the rationale for these procedures is sound, it creates a source of frustration for the sample generators as well as the laboratory performing the analysis.

It is the responsibility of the generator of the waste to initiate the appropriate forms to satisfy the waste management requirements; however, the party or group collecting the sample may not be the actual generator. In many cases the generator is long gone, along with any process knowledge related to the sample. The result is a "Catch-22." (The reason for analysis is to obtain waste characterization data, but analysis cannot be performed without these same data.) The laboratory, by virtue of potentially creating a new
Finding 7 - ICPP

procedure, WM-23 Waste

Stream Approval Process, has not been followed to ensure proper management of laboratory generated wastes.

See Recommendation 6 .

Finding 6 - LMITCO does not have an adequate system in place to manage samples of unknown hazardous characteristics.

See Recommendation 1d. 
waste stream for each unknown sample, also has to adhere to the waste management process. The laboratory essentially has to go through the same process that the sample generators go through, with the additional burden of defining the waste generated from the unknown sample as well as the waste generated during the analytical process. If information is deemed inadequate at any step, then the process is held up until new information is presented, the result of which is increased time and effort on the part of the laboratory and sample generator to obtain approval to initiate sample analysis.

Because of the recent questions regarding appropriate waste disposal at the laboratories, and the additional focus on Satellite Accumulation Area (SAA) and Temporary Accumulation Area (TAA) compliance, the ALD laboratories have adopted a strict stance on complying with the waste management procedures. The laboratory will not accept any unknown samples without the appropriate forms and has estimated it takes about $\mathbf{3 0}$ days to obtain approval for generating wastes from an unknown sample. This action has led to further frustration with site users as well as impeded the laboratory's ability to provide quick responses for analytical services.

The second issue impeding the laboratory's ability to respond on demand is the process by which funding and staffing decisions are made. Current staffing levels were established during the budgeting cycle for the current fiscal year. The mechanism to arrive at the appropriate level was to obtain a commitment from the various users of the ALD laboratories and staff to the commitments supplied by the users. During the budgeting process, according to the Laboratory Director, two events took place that affected current staffing at the laboratories. The first was a reduction in force and the second was the award of the Transuranic Waste Characterization Project (TWCP) by the Waste Isolation Pilot Plant (WIPP). This has resulted in a manpower shortage, which is causing lengthy turnaround times and limiting the laboratory's ability to handle unexpected work. These events have caused the laboratory to become less responsive to users who did not commit any funding for the current fiscal year. Laboratory management has adopted a policy of granting priority to only those customers who had made a budgeting commitment. Customers that did not commit any funding are frequently refused or are given unacceptably long turnaround times.

\section{Quality Assessment of ALD}

The ADL has demonstrated, through various proficiency evaluation programs, that it can generate accurate data. Review of its most recent performance results indicated near perfect scores. As most of these programs are run on a national basis, various agencies and laboratory users consider these programs as quality indicators. However, these proficiency evaluation programs fail to measure a
Finding 9 - The Analytical Laboratory Department is not set up to meet the needs of unplanned sample analysis, including environmental samples.

F9(a) The ALD is not funded or staffed to perform unplanned analysis.

See Recommendation 5. 
laboratory's ability to meet the regulatory aspects of sample analysis. To measure this type of quality indicator, a combination of site audits, blind sample analyses, and data validations are employed.

Data validation was performed by an INEEL subcontractor for the ALD's analysis of 1993 V-Tank sampling. The validator concluded that the analysis would not pass regulatory review. It is not clear whether the disqualification of the ALD's data was a result of the customer's failure to adequately describe the data quality objectives and subsequently the data validation criteria to the laboratory before analysis, or whether it was the laboratory's misapplication/ interpretation of the regulatory protocols resulting from the laboratory's limited experience with these methods.

Based on interviews and comments from various laboratory personnel, there is a belief that some regulatory requirements for analytical protocols either do not apply, or deviations can be made to the protocols. This belief is supported by a review that was conducted by an independent assessment team. The review covered the ALD's application of the analytical protocols with respect to analysis on highly radioactive samples.

Because good chemistry principles and the regulatory requirements often conflict, laboratory management has accepted, based on the above review, the "think like a chemist" position. Where high-level radiation samples are involved, acceptable arguments can be made to apply good chemistry principles when the regulatory requirements increase the risk to safety and/or do not account for the unique constituents or matrix of the samples. For situations involving lower radiation samples, the arguments to deviate from regulatory protocol because of safety concerns become harder to support. For sample analysis requiring regulatory determinations, permission to deviate from the regulatory requirements should be obtained from a customer and its regulators before the initiation of sampling and analysis.

Doing this before, rather than during analysis, eliminates the risk of having technically sound data rejected because of regulatory non-compliance.

The Vendor Assessment of ALD, performed by the INEEL SMO in February 1997, uncovered some generic issues regarding the strength of the llaboratory's QA program. While no indications or findings were identified that concluded that the laboratory could not produce quality data, it was noted that the laboratory was not in full compliance with all the requirements of SMO's Statement of Work (SOW). SMO's assessment only covered the radiochemistry aspects of ALD's operations.
F9(b) The ALD procedures and practices are not in full compliance with regulatory requirements for environmental analysis.

See Recommendations 6 and 8. 
During the IRT's investigation of sample handling at the ICPP laboratories, the operations of the organics and inorganics groups were briefly reviewed. Observations were made that certain general regulatory protocols were not followed; however, laboratory management provided explanations for these deviations, which were satisfactory based on the high level radiation component of the samples. In order to determine ALD's complete capability to satisfy regulatory requirements for environmental samples, it has been recommended that ALD be subjected to the same type audit that is performed for off-Site laboratories.

The award of the TWCP contract from WIPP has caused the laboratory to make a conscious effort to satisfy the customer's regulatory and SOW requirements. To perform work under this contract, the laboratory demonstrated it could implement new procedures or change operations to accommodate the quality requirements of the program. Examples of these changes were (a) generation of a project-specific quality assurance plan; (b) participation in a performance evaluation program for unknown samples; (c)generation of project-specific forms and reports, such as, sample receipt documentation, checklists and holding times, and turnaround time reports; and (d) project-specific operating procedures geared especially to the regulatory requirements placed on the customer. Many of these changes can also be incorporated into the general operations of the laboratory and serve as enhancements to other customer work. The laboratory's attempts to deal with the complex project requirements for TWCP were successful as evidenced by the recent audit by the WIPP Office. The audit identified only one finding that was related to software control and documentation. The laboratory also scored in the low 90 s for an unknown performance evaluation sample. (Ninety points out of 100 is required to continue the project.) 


\section{FINDINGS}

Finding 1 - Several cognizant and responsible organizations did not properly manage PCB wastes, found in the V-Tank system at (or from) TAN.

(a) Past contractors failed to document in records their process knowledge of waste discharged to the VTank system.

(b) Past contractors failed to maintain in a retrievable format documentation related to the waste characterization of V-Tank wastes.

(c) PPE wastes were not managed as PCB waste per TSCA.

(d) The V-tanks were not operated under adequate regulation.

(e) The generators do not always provide adequate information or documentation to perform an adequate characterization waste

(f) The generators did not apply the new characterization data to wastes still in the INEEL on-Site system on adequate characterization the site.

(g) The ability to track current locations of waste is limited to manual searches of all waste records.

(h) The 1-07B RI/FS did not contain a technical and risk evaluation for PCB contamination.

(i) The internal reviews of the RI/FS did not correct the lack of a PCB evaluation.

Finding 2 - Personnel characterizing waste are not always adequately skilled, trained, experienced, and supervised.

(a) The ER personnel did not recognize the potential for PCBs to migrate from the oil into the other waste components within the V-Tanks.

(b) The current company systems do not specify the minimum qualifications required to certify characterization of wastes.

Finding 3 - Characterization information has not been applied in a consistent manner in accordance with the regulations.

(a) The in contact rule in TSCA prohibits dilution of PCB contamination as a method to seek relief from disposal requirements. 
Finding 4 - Samples taken of TAN V-Tank system wastes and resulting analysis wastes have not been managed as known or suspected PCB-contaminated materials due to improper characterization.

Finding 5 - The SMO Task Order Statements (TOS) do not always provide all known or suspected hazardous constituent information to laboratories analyzing INEEL samples.

Finding 6 - LMITCO does not have an adequate system in place to manage samples of unknown hazardous characteristics.

Finding 7 - ICPP procedure, WM-23 Waste Stream Approval Process, has not been followed to ensure proper management of laboratory-generated wastes.

Finding 8 - On-Site and off-Site laboratories are not notified of additional waste characterization information, which is identified after samples have been sent to those laboratories, to ensure proper management of analysis wastes.

Finding 9 - The Analytical Laboratory Department ALD is not set up to meet the needs of unplanned sample analysis, including environmental samples.

(a) The ALD is not funded or staffed to perform unplanned analysis.

(b) The ALD procedures and practices are not in full compliance with regulatory requirements for environmental analysis. 


\section{Recommendation Section}

Recommendation 1 - Establish an integrated LMITCO waste stream approval process(s).

a. Integrate planning, for generation, storage, and disposal of waste. The process must fully encompass characterization, waste disposal options, pollution prevention opportunities, and tracking as appropriate to the waste generation process. The waste stream approval process (or processes) must incorporate the regulatory requirements and operational differences associated with ongoing nuclear operations, nonnuclear operations, environmental restoration, sampling activities, and waste operations. The line management responsible for generation of the waste must approve the plans and characterization. The process must be developed with full participation and endorsement by at least the following organizations: Environmental Affairs, Environmental Restoration, Nuclear Operations, Analytical Laboratory Department, and Waste Operations.

b. Full documentation and communication of waste information. The process must ensure full communication of characterization data and its basis. The planning and generation activities must account for documenting process knowledge such that it can be evaluated from records. That information must be available at all locations where the waste is handled, stored, or treated.

c. Full tracking of waste locations. The process must allow tracking of the waste such that it can be traced back to the original point of generation, and its present location, and the derivatives of the original waste can be located.

d. Laboratory handling of "unknowns." The process must have a mechanism for allowing the laboratory to analyze unknown samples. The objective of this action being the streamlining of the process to accept samples of unknown waste characteristics for analysis. The goal is to ensure the samples are analyzed within the regulatory time requirements, waste is properly characterized, and the waste is disposed of in a timely manner.

e. Qualifications of persons certifying characterization. The technical certification of the waste characterization must be performed by a qualified person. Therefore, qualifications of the persons performing the characterization certification must be evaluated. The LMITCO process must ensure the person certifying the technical characterization meets the minimum qualifications determined acceptable.

Recommendation 2 - Add direct Environmental Affairs support within Environmental Restoration (ER).

Additional professional staff are required to support ER to perform characterization of wastes, assist personnel in management of waste, review of sampling plans, evaluate project documentation, and provide regulatory evaluations. The Environmental Affairs personnel should be assigned to the Environmental, Safety, and Health (ES\&H) Compliance Officer and should be located with ER.

Recommendation 3 - A full technical and regulatory evaluation should be conducted for PCB contamination in the TSF-05 Injection Well. 
A full technical and regulatory evaluation should be conducted for PCB contamination in the TSF-05 Injection Well. The Remedial Investigation Final Report with Addenda for the Test Area North Groundwater Operable Unit 1-07B at the Idaho National Engineering Laboratory, Volume 1,

EGG-ER-10643, January 1994, should be augmented with this evaluation to address the potential for PCB contamination in the groundwater. The evaluation should be included in a modification to the ROD for Operable Unit (OU) 1-07.

Recommendation 4 - Establish full disclosure of information for waste management of sample and sample waste within the laboratory service TOS.

The disclosure process for waste management of sample and sample waste must include full disclosure of characterization and waste management information provided by the waste stream approval process. A sample submitted for analysis for which full characterization is unknown should be managed as such until characterization is obtained. A feedback process must be included to communicate the new characterization information that will permit cost-effective waste management in accordance with applicable regulations. That feedback must include the original generated waste stream knowledge from which the samples were taken. The exclusion of sample streams must be based on reasonable knowledge that sample residues will not be hazardous except as generated by the analysis method. Samples not processed through the SMO must be covered in Recommendation 1 or another process. The process must be developed with full participation and endorsement by at least the following organizations: Sample Management Office, Environmental Affairs, Environmental Restoration, Analytical Laboratory Department, and Waste Operations.

Recommendation 5 - Make a determination regarding the mission of the Analytical Laboratory Department.

Consider whether the laboratories should exist mainly for process support, or if their scope should also include support for the environmental samples for waste characterization and cleanup operations. The results of this determination should lead to decisions on the appropriate staffing and funding levels for the laboratories, a key factor of which is building in enough excess capacity in the operations to accommodate nonroutine situations.

Recommendation 6 - Subject the Analytical Laboratory Department to the same standards applicable to LMITCO Off-Site Laboratories.

If a determination is made to have the ALD continue to perform analytical testing that is used to support regulatory actions, then the laboratories should be subjected to the same levels of compliance evaluations that are used for off-Site laboratories. In addition, laboratory management must initiate a culture in the laboratory that incorporates "thinking like chemists" with regulatory compliance.

Recommendation 7 - Follow up on all waste streams generated from the V-Tank system.

A followup on any waste associated with the V-Tank system should be performed. The evaluation should consider current operations upstream and downstream from the system. The followup should ensure control of wastes and the characterization of those wastes are appropriate. 
Recommendation 8 - Determine if a Chemical Hygiene Plan is required for LMITCO laboratories

Evaluate the regulatory requirement for a Chemical Hygiene Plan (OSHA 1910.1450) for the ALD and its implementation in the company procedures. If the procedures are adequate to satisfy requirements presented in OSHA 1910.1450, then ensure ALD understands that link between the regulation and the Chemical Hygiene Plan in the procedures. Revise the procedures as needed to implement OSHA 1910.1450. 


\section{FACTS SECTION}

\section{About PCBs (Polychlorinated Biphenyls)}

The following information has been extracted from EPA document number EPA/540/s-93/506.

PCBs, also referred to by the trade names Aroclor, Phenoclor, and Kanechlor [Development of Advisory Levels for Polychlorinated Biphenyl (PCBs) Cleanup. Project Summary. EPA/600/S6-86/002, US Environmental Protection Agency. June 1987], encompass a class of chlorinated compounds that includes up to 209 variations, or congeners, with different physical and chemical characteristics [A Guide On Remedial Actions at Superfund Sites with PCB Contamination, Quick Reference Fact Sheet, U.S. Environmental Protection Agency, August 1990] Most PCBs are oily liquids whose color darkens and viscosity increases with rising chlorine content. PCBs with fewer chlorine atoms are more soluble, more amenable to chemical and biological degradation, and less persistent in the environment that those PCBs with more chlorine atoms. PCBs are thermally stable and excellent electrical insulators. [Volume 11. August 1992, pp.173-177].

PCBs are very persistent, hydrophobic, and generally do not migrate. However, there are some site characteristics that may have some bearing on the potential of PCBs to migrate. For example, PCBs in oil will be mobile if the oil itself is present in a volume large enough to physically move a significant distance from the source. Soil or sediment characteristics that affect the mobility of the PCBs include soil density, particle size distribution, moisture content, and permeability. Additionally, meteorological and chemical characteristics such as amount of precipitation, organic carbon content, and the presence of organic colloids also affect PCB mobility [Guidance on Remedial Actions for Superfund Sites with PCB Contamination. EPA/540/G-90/007, U.S. Environmental Protection Agency. August 1990. ] Determination of these characteristics during the RI/FS activities will aid in estimating the mobility of PCBs at the site.

\section{Characterizing Waste}

Under the Resource Conservation and Recovery Act (RCRA) a solid "waste" is generally any solid, liquid, or contained gaseous material that is discarded by being disposed of, burned or incinerated, or recycled. (NOTE: There are some exceptions for recycled materials.) It can be the by-product of a manufacturing process or simply a commercial product that is used in your business--such as a cleaning fluid or battery acid-that is being disposed of. Even materials that are recyclable or can be reused in some way (such as burning used oil for fuel) may be considered waste and regulated under RCRA. A material, as waste, may also be regulated as a result of other laws such as the Toxic Substances Control Act (TSCA). TSCA regulates materials/wastes containing or contaminated with PCBs at concentrations $\geq 50$ ppm.

A waste is required to be characterized to determine if it meets the definition of hazardous waste as prescribed in the RCRA regulations. The characterization is also used to determine how the waste will be treated to reduce its hazard. Characterizing waste requires a knowledge of how the waste was created, what the material was originally, how it has been altered, what are its current characteristics, and what are the applicable regulations governing it. A waste may be regulated by virtue of its history, irrespective of its current characteristics. Therefore, proper characterization is vital to determine if the laws apply to the wastes and ultimately the disposal path for the wastes. RCRA hazardous waste can be one of two types: listed waste or characteristic waste. 


\section{Hazardous Waste Defined}

"Listed waste." Waste is considered hazardous if it appears on one of four lists published in the Code of Federal Regulations ( 40 CFR Part 261). These lists are known as F, K, P, and U lists. A waste stream on the $F$ list is typically called an "F listed waste." Currently, more than 400 wastes are listed.

A common listed waste is F001, which is the following spent solvents used in degreasing: Tetrachloroethylene, trichloroethylene, methylene chloride, 1,1,1-trichlorethane, carbon tetrachloride, and chlorinated fluorocarbons; all spent solvent mixtures/blends used in degreasing containing, before use, a total of 10 percent or more (by volume) of one or more of the above halogenated solvents or those solvents listed in F002, F004, and F005; and still bottoms from the recovery of these spent solvents and spent solvent mixtures.

Wastes are listed as hazardous because they are potentially harmful to human health and the environment when not managed properly. Even when managed properly, some listed wastes are so dangerous that they are called "acutely hazardous wastes." Examples of acutely hazardous wastes include wastes generated from some pesticides that can be fatal to humans even in low doses.

Under RCRA, listed codes associated with a waste typically "attach" to anything that the waste touches. The F-codes may also apply retroactively to wastes that have already been removed from the system, but which are still in the custody of the generator.

"Characteristic waste." If your waste does not appear on one of the hazardous waste lists, it still might be considered hazardous if it demonstrates one or more of the following characteristics:

- Ignitable: It catches fire under certain conditions. Examples are paints and certain degreasers and solvents. Ignitable wastes carry the hazardous waste code D001.

- Corrosive: It corrodes metals or has a very high or low $\mathrm{pH}$. Examples are rust removers, acid or alkaline cleaning fluids, and battery acid. Corrosive wastes carry the hazardous waste code D002.

- Reactive: It is unstable and explodes or produces toxic fumes, gases, and vapors when mixed with water or under other conditions such as heat or pressure. Examples are certain cyanides or sulfide-bearing wastes. Reactive wastes carry the hazardous waste code D003.

- Toxic: It exceeds the maximum concentration of at least one of the RCRA toxicity contaminants following the performance of the toxicity characteristic leaching procedure (TCLP). Examples are wastes that contain high concentrations of heavy metals, such as cadmium (D006), lead (D007), or mercury (D004). Toxicity characteristic wastes carry the hazardous waste codes D004 - D043 (or higher as new wastes are added).

\section{Hazardous Waste Generation}

The typical construction activities could generate hazardous waste by paint preparation and painting; carpentry and floor work; other specialty contracting activities; heavy construction, wrecking and demolition; and vehicle and equipment maintenance for construction activities. The types of wastes generated could include ignitable wastes, toxic wastes, solvent wastes, paint wastes, used oil, and acids/bases. These would have the waste codes D001, D002, and F001 through F005. 
The typical laboratory activities could generate hazardous waste by diagnostic and other laboratory testing. The types of wastes generated could include spent solvents, unused reagents, reaction products, testing samples, and contaminated materials. These may be considered characteristic waste (e.g., D001, D002, D003) or listed (F001 through F005, and U211) depending on the point of generation and process knowledge.

\section{Technical Support Facility Intermediate-Level Waste Disposal System (ILWDS)(TSF-09)}

Located at TAN is an ILWDS, which collected, processed, and provided interim storage capacity for all intermediate-level radioactive liquid waste generated at the TSF. Tanks were used to collect radioactive liquid waste from the following facilities: TAN Hot Shop, TAN Decontamination Shop, various TAN-607 laboratories, TAN Hot Cells, TAN Craft Shops, and the Initial Engine Test (IET) Facility. Drains and sumps located in these areas with a high potential for contamination were piped to a waste transfer facility (TAN-616). There, the radioactive liquid waste was collected in one of three underground 10,000-gal stainless-steel collection tanks (V-1, V-2, or V-3). These tanks are located immediately northeast of TAN616 between TAN-615 and TAN-633 (see Figure 2). From that point on, the process for handling these intermediate-level wastes has changed over time. Figure 3 depicts flowcharts for the three different systems that have been used to process this waste, and the dates associated with the system changes.

From 1955 to 1972 , liquid waste from the 10,000-gal collection tanks was concentrated by an evaporator, and the concentrate was transferred to tanks T-710A and T-710B (also known as the PM-2A storage tanks V-13 and V-14, respectively) for long-term storage. T-710A (V-13) and T-710B (V-14) are both 50,000-gal) underground tanks located south of the railroad track turntable and Snake Avenue. The condensate from the evaporator was then sent to the TSF-05 Injection Well.

In the late $1950 \mathrm{~s}$ and early $1960 \mathrm{~s}$, the evaporator concentrate in the bottom of the T-710A (V-13) and T-710B (V-14) tanks was pumped out by TAN facilities personnel and put into the injection well. No samples were taken of the material during this time.

The TSF ILWDS was designed to receive and treat waste too radioactively contaminated to be discharged to the TSF disposal pond. Any hazardous chemicals reaching this system were incidental to the processing of radioactive materials. The system potentially received corrosive materials from decontamination activities and, in some instances, heavy metals, particularly mercury, during its extensive usage in the late $1950 \mathrm{~s}$ and early $1960 \mathrm{~s}$. Also, small quantities of potassium chromate were used in decontamination solutions from 1970 to 1974 . (Reference: Page 82 in the "Informal Report" EGG-WM6875, January 1986).

In approximately 1968, a large quantity of oil was discovered in the V-2 Tank and the tank was taken out of service (reference: EG\&G Idaho, Inc., Radiological Characterization and Decision Analysis for TAN-616 Liquid Waste Treatment Facility, WM-FI-83-012, September.) About 60 gallons of oil were separated from the water and removed from the tank in 1981. The water in the three tanks was removed in 1982. 


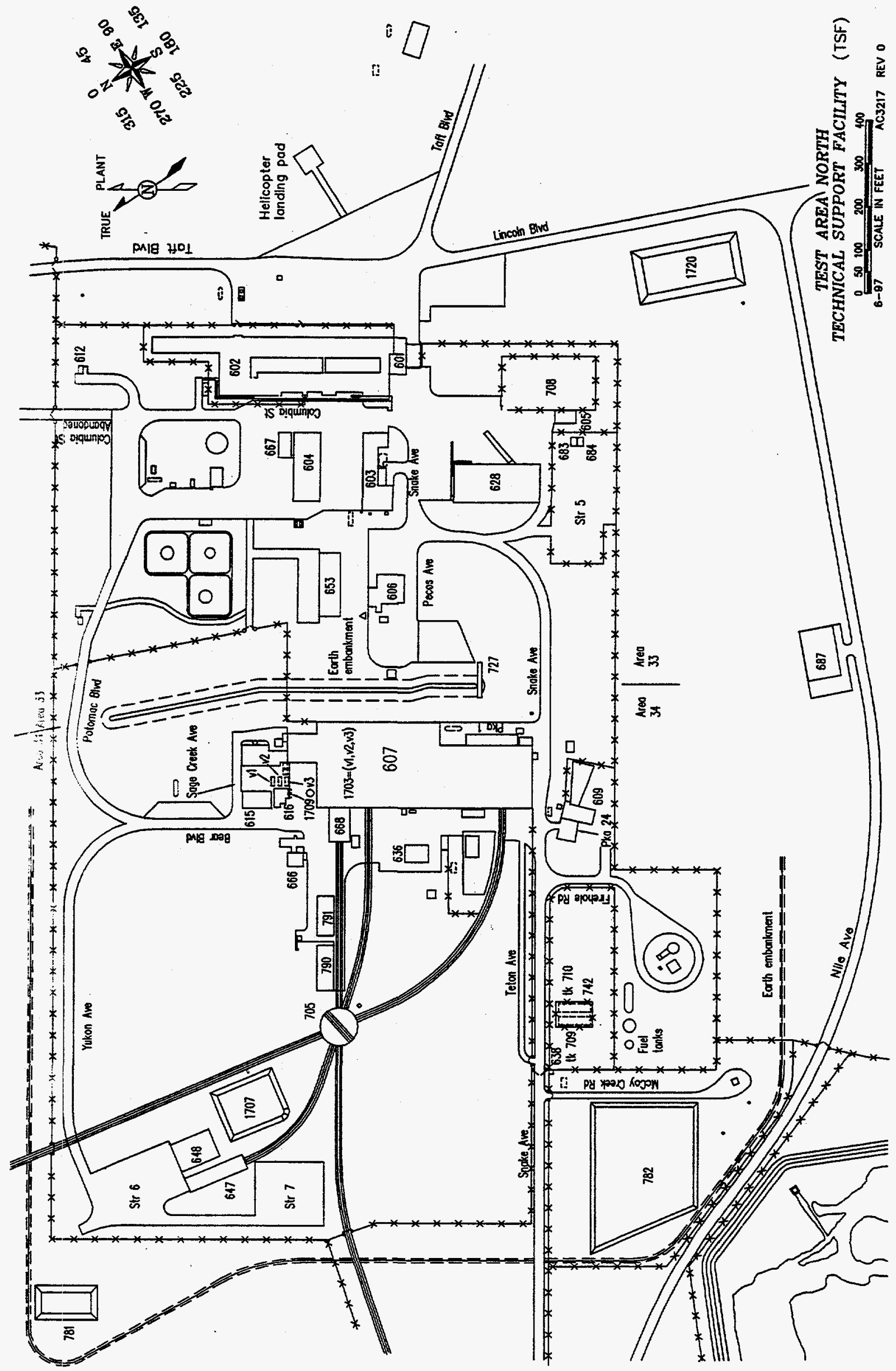

竎 


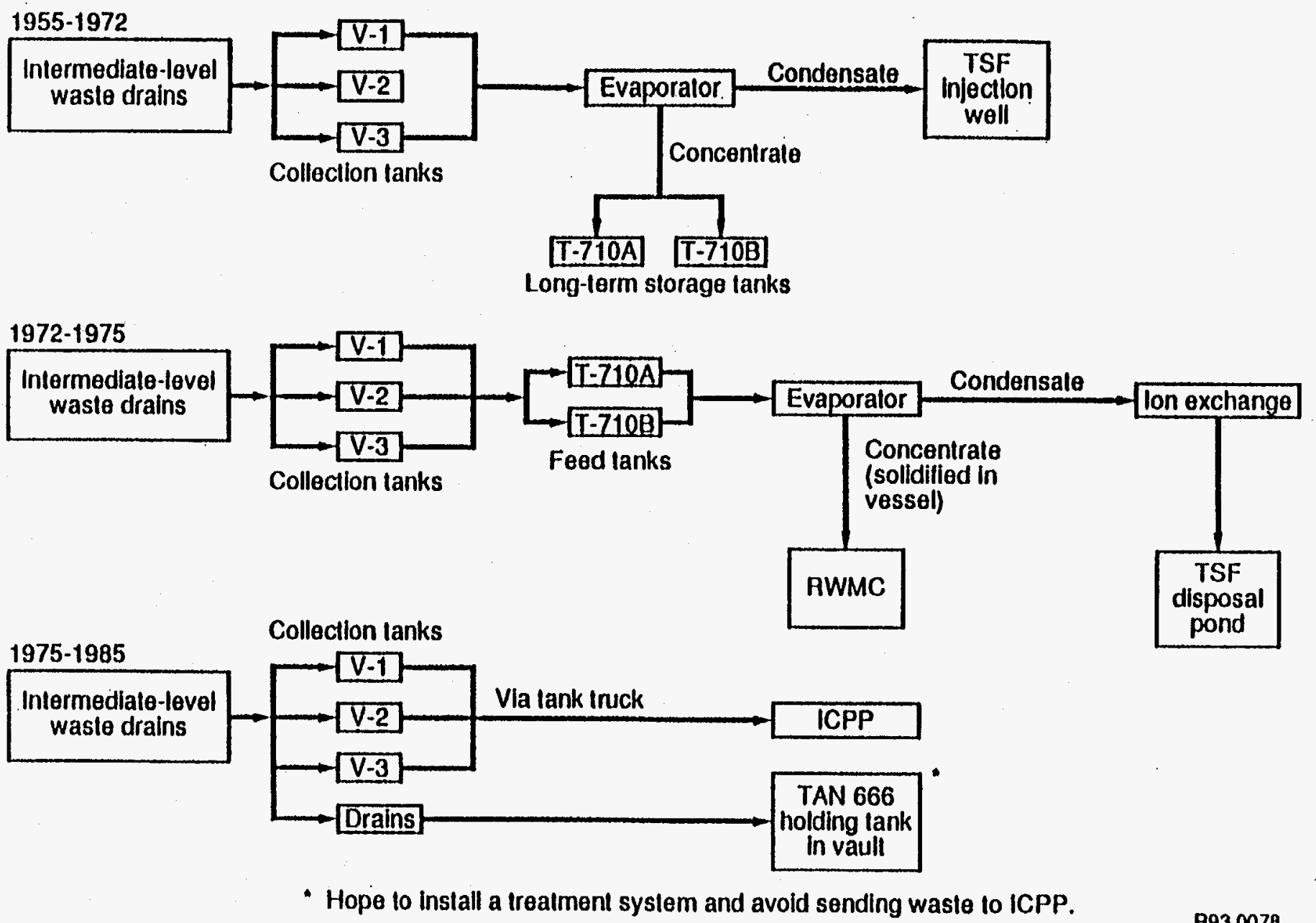

Figure 3. TSF flowcharts of the intermediate-level liquid waste system. 
In 1972, the liquid waste process was modified so that the original evaporator downstream of the V$1, \mathrm{~V}-2$, and V-3 Tanks was removed and a new evaporator installed in the T-710A (V-13) and T-710B (V-14) Tank area. The intermediate-level waste was then collected in the V-1, V-2, and V-3 Tanks and pumped directly to T-710A (V-13) and T-710B (V-14), which served as feed tanks for a subsequent stainless steel evaporator. The liquids and entrained radioactive solids were separated in the evaporator; the solids remained in the evaporator vessel, which provided interim storage during processing and also served as the long-term storage container. When filled to capacity (about 20 tons), the semisolid radioactive waste was solidified by evaporation, and the container was transferred to the Radioactive Waste Management Complex (RWMC) for disposal. Distillate from the evaporator flowed to the condenser and then to a condensate storage tank. The condensate was passed through a fabrication ion-exchange column for further removal of radioactive ions. Effluent from the ion exchanger was combined with other TSF low-level radioactive liquid waste before being discharged into the TSF disposal pond. The newer evaporator system was shut down in 1975. Because of operational difficulties and spillage, the system was never put into full operation. Since 1975, the TSF intermediate-level waste had been collected in the V-1, V-2, and V-3 Tanks and then transferred to tank trucks and shipped to ICPP. The last of these shipments, per interviews, was in the 1984-85 timeframe.

No records were found that show which hazardous chemicals may have passed through the evaporator (when it was in use) and into the condensate stream. It can be assumed that the concentrate from the evaporator system may have contained small quantities of hazardous chemicals, and these concentrates were eventually solidified before disposal at RWMC. The RI/FS (EGG-ER-10643) stated the hazardous chemicals identified so far; especially the metals, should pose little problem in a solidified form.

The RI/FS also stated from the 1960 s to 1975 , the majority of the radioactive material discharged to this system was eventually disposed of at RWMC. The lesser amounts of radioactivity that were discharged in the condensate to either the TSF disposal pond or TSF-05 Injection Well were included in the quantities discussed earlier. The radioactivity in the sludges discharged to the injection well is not believed to have been included in the INEEL's Radioactive Waste Management Information System (RWMIS).

\section{The TSF-05 Injection Well}

The TSF-05 Injection Well was drilled in 1953 to a depth of $305 \mathrm{ft}$ to dispose of liquid effluent generated from the ANP project. The TSF-05 Injection Well has a 12-in. diameter casing to $305 \mathrm{ft}$ and is perforated from 180 to $244 \mathrm{ft}$ and 269 to $305 \mathrm{ft}$ below land surface. The depth to groundwater is about $206 \mathrm{ft}$ below land surface. The well was last used as a disposal site in September 1972, after which wastewaters were diverted to the TAN disposal pond.

Discharges to the well included organic slugs, treated sanitary sewage, process wastewaters, and low-level radioactive waste streams. Historical records provide little definitive information on the types and volumes of organic wastes disposed via the injection well. Based on the results of groundwater quality analyses from the injection well, as well as from analytical and radiological analysis of sediment and sludge removed from the well in 1990, the TSF-05 Injection Well is the primary source of groundwater contaminants at TAN. Since 1988, elevated concentrations of trichloroethylene (TCE) and other volatile organics have been detected as a result of several sampling efforts by the United States Geological Survey (USGS) and EG\&G Idaho. EG\&G Idaho groundwater quality data from these past sampling events show TCE concentrations at the wellhead ranging from $16,000 \mu \mathrm{g} / \mathrm{L}$ to $28,000 \mu \mathrm{g} / \mathrm{L}$, while data from the USGS show concentrations of TCE up to $35,000 \mu \mathrm{g} / \mathrm{L}$. Tetrachloroethene (PCE) and 1,2-dichloroethylene (DCE) were also detected at concentrations above drinking water standards. 
During January and February 1990, 55 linear $\mathrm{ft}$ of sediment and sludge (from well depths between 250 and $305 \mathrm{ft}$ ) was removed from inside the well casing. Analysis of this material indicated very high $(\sim 2 \%)$ TCE concentrations in the sludge, as well as elevated concentrations of radiological and metal constituents such as tritium and cesium. The RI/FS does not indicate an analysis for PCB contamination was performed on the sludge.

A Groundwater Treatment Facility (GWTF) was constructed at the TSF-05 Injection Well to treat the water. It went into operation in February 1994. The system was fouled with what was believed to be food grade oil within the first 8 hours of operation. The GWTF was restarted at a lower flow rate after a maintenance period. The original flow rate caused a local depression in the groundwater, which caused the oil in the area to reach the system intake. The GWTF has a bag filter system that removes sludges during the treatment process. The ER ES\&H Compliance Officer stated samples taken from the sludges in April 1995, indicated a PCB content of 2-7 ppb. The oil was not sampled.

Reference: Remedial Investigation Final Report with Addenda for the Test Area North Groundwater Operable Unit 1-07B at the Idaho National Engineering Laboratory, Volume 1, EGG-ER-10643, January 1994.

\section{TAN V-Tank Operation History Including Waste Management}

In the late 1970s, several of the TAN V-Tanks were taken out of service and turned over to the Decontamination and Decommissioning (D\&D) Department of EG\&G Idaho's Waste Programs Branch for removal. According to a current employee, who served as the D\&D Supervisor during this time period, there was no funding available in the late 1970 s or early 1980 s for removing the tanks. D\&D decided, through their planning process in 1980 , to leave them in safe storage until funding could be obtained. He said it was decided at that time, to minimize risk and ensure safer storage, that D\&D would remove the liquids from the V-1, V-2, V-3, V-13, and V-14 Tanks.

On 6/10/87, the TAN V-Tanks were added to the 1987 Consent Order and Compliance Agreement (COCA). On 12/09/91, the tanks became part of the 1991 Federal Facilities Agreement and Consent Order (FFA/CO). Today LMITCO's ER organization manages the V-Tanks under the CERCLA program. The following is a brief synopsis of events associated with those removal processes, and additional history associated with the tanks including sampling events.

\section{TAN V-Tanks V-1, V-2, and V-3}

Located just north of TAN-607, (see Figure 2) the V-1, V-2, and V-3 tanks have been sampled numerous times over the past 18 years. Samples were generally taken for radiation analysis only as this was the risk being considered, however, some samples have been analyzed for other hazards including PCBs. In the 1980-81 timeframe it was determined that oil contained in the V-2 Tank was PCB contaminated (reference Informal Report EGG-WM-6875, January 1986). It is not clear when the PCB concentration of the waste was determined, though a PCB concentration of 680 parts per million (ppm) is referenced in a 1986 informal report. This concentration is also included on the waste profile information document used to ship this oil to the Mixed Waste Storage Facility (MWSF) for storage in 1986. The cause of this contamination (or when it occurred) is unknown, but it is suspected that a ruptured hydraulic fluid line on a piece of equipment inside the TAN-607 Hot Shop was the source as early as 1968 or before.

The initial D\&D plan was to drain all of the liquids from the V-1, V-2, and V-3 Tanks. The plan was to then ship the liquid to the ICPP for disposal in their hot waste tank system (reference EG\&G Idaho 
report WM-F1-81-081). However, due to safety and criticality requirements associated with the waste disposal system at ICPP, the facility could not accept the oil that floated on top of other aqueous liquids in the tank, so D\&D had to separate it.

In August of 1981, D\&D removed approximately 60 gallons of oil from the V-2 Tank separating it from the aqueous liquids. Waste flows to and from the V-Tanks are shown in Figure 1. The oil remained in storage at TAN until 4/25/86, when TAN's Environmental Coordinator shipped the oil in two drums (bar codes 698 \& 699) to the MWSF for storage. At this time the EG\&G Idaho Waste Operations group assigned Waste Stream ID Number (WSID) 1002 to the waste for tracking purposes. The rest of the history associated with this oil waste stream is described below in the "V-2 Tank Oil WSID 1002" section of this report.

The oil separator equipment used in separating the V-2 Tank's oil from the liquids was shipped to the RWMC for disposal. This team was not able to determine if this equipment was decontaminated, or managed in accordance with TSCA.

In April of 1982, a total of 8,300 gallons of liquid (mostly water) in the V-2 Tank was subsequently removed, transported by tanker, and disposed of in ICPP's PEW system. This liquid was not sampled to determine PCB concentrations, though reports indicate that a sheen of oil remained on the liquid. On 4/26/8?, while removing the liquids from the V-2 Tank, an incident occurred when the vent and fill line connections on the tanker were reversed releasing an estimated 1730 gallons to the immediate area. In response to this spill, D\&D removed approximately 128 cubic feet of contaminated soil and shipped it to the RW/MC for disposal (reference Unusual Occurrence Report EGG-82-92). There are no indications that the soil was tested for PCBs. The area was then covered with approximately 2 to 3 inches of clean soil. No documentation was located by the IRT that indicated that any of the sludge was removed from the tanks at this time.

A holding tank, TAN-666, was installed replacing the part of the system associated with TAN-616.

TAN-666 went into operation around 1987. Shortly after the removal of the liquid from the V-2 Tank, TAN had problems with this holding tank and the V-1, V-2, and V-3 Tanks were reactivated. Employees interviewed stated that the tanks remained in service until the 1984-85 timeframe. During this time, when the tanks reached capacity the waste was again sent to the ICPP PEW. Interviews with those who have been sampling the wastes, and those who have worked at TAN for some time indicate that when the tanks were again removed from service, the liquids in them at the time were not removed. The tanks still contain sludge and liquids.

Test Area North Operations (TANO) is an organization that manages the TAN Hot Shop, Hot Cell Annex, Fuel Storage Pools, the RPSSA, and the fuel cask pads. TANO reports to the Nuclear Fuels Directorate located at ICPP. TANO has been checking the level of the V-Tanks for years with a measuring stick. The personnel raised the stick out of the tank then placed the stick back in the tank where it is stored. Employees who do this checking process stated that liquid is not wiped off the stick during these checks, and PPE never contacts the liquid on the stick. The PPE waste is handled as LLRW.

Documentation dated 1/05/96, indicates that LMITCO's ER Department determined in 1995 that the

V-3 Tank's liquid level was rising. This documentation indicates that they suspected the cause of the rising levels was due to runoff from snow and rain entering the tank through an access cover. ER 
personnel stated that ER replaced the gaskets and installed a high-level alarm before spring runoffs to correct this situation and to ensure real-time monitoring.

There have been numerous sampling events associated with the TAN V-Tanks. Those that were identified by the IRT are as follows:

- In 1979, the V-Tanks were sampled for the D\&D organization; no documentation was found by the IRT that indicated what types of analysis were conducted.

- In 1980, the V-Tanks were again sampled for the D\&D organization; no documentation was found by the IRT that indicated what types of analysis were conducted.

- On 2/28/90 the EG\&G Idaho Environmental Monitoring Unit sampled liquid in the TAN-666 holding tank interconnected with the V-Tanks. Samples were sent to the TRA Radiation Measurement Laboratory (RML) and to the Central Facilities Area (CFA) Experimental Chemistry Unit (ECU) laboratory. Documentation identified did not clarify if this sampling included the V-Tanks. The IRT could not determine what was done with these samples or the sample analysis wastes following analysis.

- Between June of 1990 and July of 1991, the EG\&G Idaho Environmental Technology Unit (ETU) sampled the V-Tanks and sent the samples to the INEEL's ICPP Remote Analytical Laboratory (RAL). These samples were returned to the ETU on 7/07/91. The IRT did not determine what was done with the sample analysis wastes. This sampling was for radiation only-no analyses for PCBs were conducted at this time.

- In September of 1993, EG\&G Idaho's ER Department conducted a CERCLA investigation of the TAN V-Tanks. Samples were taken to characterize the liquid and the sludge in the V-1, V-2, and V-3 Tanks and shipped to the ICPP RAL. This sampling was for radiation only-no analyses for $\mathrm{PCBs}$ were conducted at this time.

- In 1996, V-Tanks 1, 2, 3, 9, 13, and 14 were sampled for LMTTCO's ER Department. Samples were sent to ICPP's ALD laboratories and to a Babcock \& Wilcox off-Site laboratory. Samples were analyzed for PCBs and results indicated PCB concentrations of various ranges.

- In 1993, the Specific Manufacturing Capability (SMC) laboratory personnel sampled building TAN-616. SMC personnel interviewed said smear samples and samples of residues in the tanks within the building were taken. The samples were sent to ICPP for analysis. None of the samples were analyzed in the SMC laboratories. The PPE and drill bits associated with this sampling were reported to have been left in the building. The samples were analyzed for PCB, TCLP metals, volatile, semivolatile, gross alpha, gross beta, gamma, and isotopic uranium. A report of the sample results was issued in September 1994. The IRT did not review the report.

\section{V-2 Tank Oil, WSID 1002}

This section of this report is written to reflect the history and the current status of the 60 gallons of oil removed from the TAN V-2 Tank in 1986.

Waste Stream ID Number (WSID) 1002 was created by EG\&G Idaho's Waste Reduction Operation Complex (WROC) personnel to track the 60 gallons of V-2 Tank oil shipped to them from TAN in 1986. Documentation completed for shipping the waste to the MWSF from TAN, included the Uniform 
Hazardous Waste Manifest, dated 4/24/86 and a Generator's Hazardous Waste Material Profile Sheet. The profile sheet indicated that this oil contained $680 \mathrm{ppm}$ of PCBs and referenced EG\&G Idaho Report WM-F1-83-012, September 1983 (the reference report included no PCB analysis, only radiation data). To date, the IRT has not located the analytical results that document the assignment of this PCB concentration to the waste oil. However, this concentration level is stated in EG\&G Informal Report, EGG-WM-6875, January 1986, and is reasonable as results from 1996 sampling activities were similar.

On 7/11/94, the MWSF used an "Exclusive Use Shipment" to send the oil to the TAN Hot Shop, where it was sampled for a TSCA treatability study (reference Uniform Hazardous Waste Manifest 94006). This sampling was done per WROC Sample Analysis Plan (SAP)-6.16. The samples were sent to the RML at TRA with a request for gamma-ray analysis as well as other radiation analysis. A teleconference call with WROC personnel indicated that after analysis, the samples and rinsates were returned to the generator (WROC) and placed back in the parent containers. This waste was later returned to the MWSF on 7/19/94, (reference Uniform Hazardous Waste Manifest 94008) where it is currently in storage.

In June of 1995, WROC created a new waste stream for the 1994 samples and rinsates giving it tracking number WSID 1716. The samples were packaged with other samples generated for the treatability study, from the same sampling project in a container numbered Barcode 9852 , and shipped to the MWSF on 6/22/95. This waste stream, per WROC personnel, includes a mixture of wastes from the 1994 treatability studies.

On 4/22/96, WROC MWSF personnel noted that an Out of Service (OOS) date of $8 / 29 / 80$ had been assigned to this waste oil from the V-2 Tank.

In May of 1996, Uniform Hazardous Waste Manifests 96004 and 96035 indicated the oil (WSID 1002) was returned to the MWSF from the TAN Hot Shop. It had previously been sent there and consolidated with four other PCB waste streams. This consolidation effort was in preparation of shipping the waste to the ORNL for disposal at that facility. At that time, the repackaged waste, described as Consolidated TSCA Oil and Sludge, was then assigned WSID 1987 by the MWSF. Samples were pulled of the consolidated oils for analysis needed to meet the ORNL acceptance criteria.

The consolidation samples were shipped, through the LMITCO SMO, to the following off-Site laboratories: WESTON, and S-Cubed, South West Research. The SMO also sent samples to the laboratories at TRA and ICPP. WROC personnel interviewed indicated that identification labels were placed on these samples and they were marked "contains PCBs" as was the Chain-O-Custody documentation. Per WROC personnel, all of the samples analyzed on-Site, except the TRA samples, were returned to MWSF under the same waste stream ID number of the parent and packaged in a separate drum from the parents. They also said that the ICPP and TRA laboratories sent the sample residues back and the MWSF added those to the new waste stream created for the repackaging effort (WSID 1987). It was noted, however, that WROC personnel said they were not certain as to why TRA did not return the samples with the residuals, as that was what WROC stated they had requested be done. Per WROC, those samples have now been moved to a TRA TAA and will be returned to WROC in the near future. The PPE from the repackaging operation was given the tracking number WSID 1988.

WROC personnel interviewed also indicated that the contracts set up with the off-Site laboratories required those laboratories to dispose of any altered samples and analysis wastes. The LIMTCO SMO was asked to verify this information. They reported that current contracts do require off-Site laboratories to dispose of analysis wastes and altered samples, unless they are PCB contaminated. However, in further 
discussions with WROC indicated that the PCB-contaminated analysis wastes were not returned to them. The IRT notified the SMO for followup.

On 9/16/96, the ICPP WMA Coordinator notified the Environmental Support Supervisor that WROC was having ash samples from a waste stream associated with the V-Tanks analyzed at ICPP. The coordinator stated the listed "F" codes were not assigned to the waste. Documentation in the WMA files indicates this concerned him because ICPP had previously analyzed samples from the same source (TAN V-Tanks) for ER. The document showed F001 and F002 codes were assigned to the samples. The WMA Coordinator indicated to the IRT that the WMA wanted to ensure that the waste codes assigned to this waste were assigned consistently.

No hazardous waste codes were indicated on any of the manifests associated with the 1002 waste until the repackaging effort when the D008 and D018 codes were added, which carried from the other wastes with which 1002 was consolidated. The listed code (F001), which is now assigned to the V-Tank waste, has not yet been added to the waste (reference the Hazardous Waste Determination Record, dated 1/22/97, for the Initial Engine Test TSF-21 Valve Pit). This listed code also has not yet been added to all of the PPE and sampling waste associated with the repackaging effort. WROC personnel indicated that they have not officially been notified that the listed codes apply to this waste at the time of this investigation.

During interviews with the various personnel who have been associated with the past and the current management of the V-2. Tank waste, they stated that they were not aware that there was any waste from these tanks still stored at WROC. Thus neither they nor ER notified the facility of the applicability of RCRA listed codes to the waste oil when that applicability was determined. At the time that this report was written, WROC still had not been "formally" notified that the listed waste codes should be applied to the waste, though Environmental Affairs (EA) personnel had contacted them to make them aware of this issue.

\section{V-Tank Sampling and Analysis Scenario Including Waste Management}

On 9/22/93, the V-1, V-2, and V-3 Tanks were sampled by EG\&G Idaho's ER organization. Samples were sent to ICPP's RAL for analysis and labeled "radioactive low specific activity." The TOS developed for this analysis contract did not mention that the samples could be contaminated with TSCA levels of PCBs, nor did the Chain-of-Custody documents. However, various laboratory personnel interviewed stated that the laboratory had been verbally asked to analyze for PCBs. The laboratory could not respond to this request in 1993, as they did not have the capability to analyze for PCBs at that time.

On 9/22/93, a jar containing two of the sludge samples sent from the V-2 Tank was broken in the RAL hot cell. In addition, a second sample from the V-1 Tank was ruined when laboratory personnel tried to manipulate a jar containing the sample in the hot cell. The jar rolled away from them coating the insides with the sample material-not leaving enough for analysis. These broken V-1 and ruined V-2 samples were rinsed down the drain leading to ICPP's PEW. The laboratory estimated that approximately 1 to 2 liters of rinses and wash waters would have been drained to the PEW from this analysis event. Though the laboratory did not analyze these samples at that time for PCBs, samples taken from the same tanks in 1996 and analyzed by an off-Site laboratory indicated PCBs ranges were from 160 to $260 \mathrm{ppm}$ in the V-2 Tank, and $660 \mathrm{ppm}$ in the V-1 Tank

On 9/22/93, a form was submitted to the ICPP WMA for this waste stream. Per documentation, approval was not granted for generation of this stream until the following day. On 9/23/93, a WMA tracking number, WMA 93013, was assigned by the WMA for this sampling analysis waste stream. The 
WMA had not been informed of the PCBs associated with this waste stream. The current and the past WMA Coordinators interviewed both stated that the WMA would never have approved of putting a PCBcontaninated waste stream down the PEW drains, as direction to them from Environmental Protection supervisors has always been that that was prohibited. WMA meeting minutes indicate that the WMA expressed major concerns regarding this waste stream as the tank samples were from material that was unknown. Because the samples were unknown, the WMA said that special considerations should be made by the laboratories to determine if the waste met all acceptance criteria for the liquid waste systems before generation. A note was added to the last section of the WMA form instructing the laboratory to "accurnulate all waste possible until determined to meet PO-40 and Westinghouse Idaho Technologies Company (WINCO) Waste Acceptance Criteria." Approval to generate the waste was then provided on the form.

The IRT noted that the samples were received at the ICPP RAL before the WMA forms were approved by the ICPP WMA. Thus the broken and inadequate samples were rinsed down the PEW before that approval. Except for the waste from one sample, all wastes generated after the WMA form was issued, which were not PEW compatible, were collected and stored before being shipped to the INEEL WERF incinerator in 1996 (reference WSID 1953 described below). All analyses residues thought to be PEW compatible were rinsed down the PEW drain.

During a telephone interview with laboratory personnel, they said that in 1994, though the laboratory did not have calibrated methods set up for PCB analysis, they did have the capability to screen samples for PCBs. They said that in response to their customer's 1993 request, the laboratory did a screen of 1993 samples. These samples were saved as requested by the customer and were still at the laboratory. From this screening they were able to notify the ER Project Manager that they had identified PCBs in these samples in concentrations of $48 \mathrm{ppm}$ and $99 \mathrm{ppm}$ (as indicated by documentation reviewed by the IRT.) They said that they reported this for information only, as they still did not have approved calibrated sampling methods set up. This analysis information was not forwarded to the ICPP WMA, therefore, the WMA was never aware that the laboratory had identified PCBs in the samples.

Though all of the high chloride waste generated in the 1993 analysis, which was not compatible with the ICIPP PEW, was still in storage, the laboratory did not apply TSCA to the management of this waste following its 1994 screening. Interviews indicate that personnel cognizant of the screening results were not aware that 1993 waste was still stored at ICPP-1617. In addition, laboratory personnel said that they did not consider the screening results to be of a regulatory value, as the methods used for this screening were not approved methods and the equipment was not calibrated. The laboratory indicated that they still had not been told by Environmental Restoration that the waste in the V-Tanks was TSCA regulated, and that the TSCA concentration of PCBs at $680 \mathrm{ppm}$ would apply to the waste associated with this sample analysis project.

On 1/10/94, an interoffice correspondence was sent from the person who had been the lead sampler in 1993, to the then ER Project Manager responsible for the V-Tanks (reference V-Tank Sampling Summary Report IRA-01-94). This report summarized the 1993 V-Tank sampling events. It clarified for the ER. Project Manager details including the sampling dates of 9/21/93-9/29/93 for the V-Tanks. The letter indicates resulting samples were delivered to ICPP and according to the report, received in acceptable condition. The report concludes with a summary of the samples collected and the analysis parameters requested for each sample. The analysis requests include PCBs, though this was not incorporated into the TOS provided to the laboratory by EG\&G Idaho in contracting the analysis work. 
On 1/12/95, while working to help the laboratory ensure proper characterization of the sample wastes being generated in support of the TAN V-Tank sampling efforts, ICPP Environmental Support characterization personnel questioned whether there were RCRA waste codes as well as TSCA concerns associated with the V-Tanks (reference characterization files). Notes indicate that they contacted the ER organization (the generator) to obtain characterization information. Though the ICPP screening information was not known to ICPP characterization personnel, personnel interviewed said and documentation indicated that these characterization personnel had become aware that there could be TSCA concerns with the V-Tank waste and thus the samples from that waste. The same characterization personnel worked to resolve this until they left the company as is evident by notes reviewed by the IRT. Their notes indicate they believed the waste to be PCB contaminated to $680 \mathrm{ppm}$ and possibly listed hazardous waste.

On 4/17/96, and again on 4/30/96, high chloride/high sulfate wastes from laboratory analysis conducted at ICPP, including the 1993 V-Tank analysis waste, were shipped to the WERF incinerator for disposal. Before shipping, the waste was sampled to obtain information needed to meet the WERF facility's WAC.

For tracking purposes, the waste stream was given a WSID 1953 by WROC personnel when it was shipped (this waste is described further below). This waste was incinerated during the 1996 WERF burm campaign.

\section{RAL High Chloride Waste, WSID 1953}

Identified on WROC documentation as "Aqueous Corrosive Laboratory Wastes," this combination of three analysis waste streams from the laboratory has an indirect relationship to the 1993 TAN V-Tank sampling event. This waste was shipped from ICPP storage to the WERF incinerator in 1996, and incinerated in a burn campaign in that same year.

On 4/17/96, and on 4/30/96, 18 containers of high chloride/high sulfate waste, generated in analyzing various samples at ICPP's ALD laboratories, were shipped to WERF. The waste included liquids and solids (PPE, paper, and gloves). This waste was shipped as mixed low-level waste. Shipping papers do not indicate PCBs (reference Uniform Hazardous Waste Manifest and L-0669A Form). A routine waste stream, this stream had been assigned a WMA tracking number by the ICPP WMA of 95137. WROC personnel managing stored waste at ICPP said there were three combined waste streams associated with this waste including: (1) WINCO's ICPP sample analysis waste generated from the analysis of the 1993, EG\&G Idaho, ER TAN V-Tank samples (assigned WMA 93013), (2) waste from Auxiliary Reactor Area (ARA) 729 Tank samples, and (3) TRA Catch Tanks sample analysis waste.

Various RCRA hazardous waste codes were identified on Attachment A of the Uniform Hazardous Waste Manifest (D, P, and U codes, as well as F002 and F005 codes), however, F001 found on the WMA Form was not included. The WMA Form WMA 93013, (never approved) for the TAN sample analysis VTank waste, was marked PCB TSCA and included F001 and F002 codes. The current WMA Coordinator, who had worked with the past ICPP characterizer trying to resolve some of these characterization questions, said during interviews that the " $F$ " codes had been included per information provided to the ICPP WROC environmental characterization personnel by the sample generators (ER) of the 1993 samples. ICPP WROC personnel told IRT members during a telephone interview that the WMA Form information was not communicated to the shippers at ICPP responsible for completing the manifest, which was the generator's (ALD) responsibility not the WMA Board's. The IRT noted that the WMA was 
unaware that the waste had actually been shipped for disposal. It was not clear to the IRT as to why the F001 code was dropped.

As PCBs were not indicated on any of the shipping documentation for this waste stream, or in any communications with the WROC facilities including the WERF incinerator, those disposal facilities were unaware of the presence of PCBs in the waste. Though the laboratory had screened 1993 samples in 1994 and identified PCBs, they did not incorporate that knowledge into their waste management of the 1993 generated wastes stored at ICPP until 1996. The IRT's findings regarding this failure are as follows:

In 1994, the ICPP ALD laboratories performed a screening analysis of some of the 1993 V-Tank samples indicating PCBs of TSCA regulated levels (reference the 1993 sampling analysis described above). There were numerous contributing factors as to why the ICPP ALD laboratory did not incorporate the 1994 screening information into the management of the WSID 1953 waste stored at ICPP until 1996.

First: The laboratory's point of contact (POC), who was in charge in the 1993-94 timeframe, was not the same POC, who was in charge during the 1995-97 timeframe. Historical information known by the first POC, was not totally communicated to the second POC. This historical information would have indicated that the 1993 V-Tank samples were split. The first samples were analyzed in 1993 and the second samples were analyzed in a screening in 1994 . Those that were analyzed in 1993, were sent to ICPP-1617 where they remained in storage until 1996. Those that were screened in 1994, remained at the laboratory until no longer needed-stored for disposal in 1996. This splitting of the samples created two separate waste streams later tracked as WSID 1953 and WSID 1971.

Second: When the waste stream, WSID 1953, was shipped to storage (where it remained until 1996), the laboratory had not analyzed for PCBs, nor had they yet been notified that PCB contaminated oils (of a TSCA regulated level) had previously been removed from the V-Tanks. Therefore, the need for managing this waste stream in accordance with TSCA was unknown in 1993, and thus not communicated to the storage personnel at ICPP-1617.

Third: When the laboratory screened the second part of the '93 V-Tank samples, the screening was done for information only--using equipment that was not calibrated and methods that were not EPA approved. Interviews indicate laboratory personnel did not consider the results to be of a regulatory management value. Their reason was that although PCBs were detected at TSCA-regulated levels, it was through using uncalibrated equipment and the data and was not validated. Therefore, TSCA management was not imposed on the second part of samples screened in 1994, nor was it applied to the first part of the '93 sample analysis waste already in storage.

Fourth: the POC, who managed the laboratory's waste in 1993, indicated that in 1993 he did not know that WROC WERF personnel needed to know about PCBs in waste if the PCB levels were below TSCA regulated levels.

Fifth: Interviews indicated the POC, who managed the laboratory's waste in the 1995-97 timeframe, stated that he was unaware the first part of the 1993 sampling waste (WSID 1953) was stored in ICPP-1617 in 1996, though at the time he was working to properly characterize and arrange for disposal of the second part of the waste (WSID1971) created from the 1994 screening. Interviews further indicate the POC was unaware that the ICPP-1617 storage facility personnel were also working to further characterize the stored, first part of the waste (WSID 1953) eventually, and that they were unaware that he was working to characterize the second part. He 
was not aware that ICPP-1617 personnel had need of the TSCA-related information and that they were not aware that he had it. He had no knowledge indicating that the first part of the waste (WSID 1953) was shipped to WERF for incineration. If he had known about the storage of the first part of the 1993 sampling, he could have communicated and incorporated the TSCA information he had recently obtained for the second part of that same waste (WSID 1971)possibly preventing its incineration.

Before shipping this waste to WERF, the wastes were sampled at WROC's request. The current ALD POC and the current WMA Coordinator indicated to the IRT that the sampling was done for criteria specified by the WROC WGI interfacing with ICPP sampling personnel. As stated above, interviews indicated that laboratory personnel, cognizant (in 1996) of PCBs associated with the V-Tanks, were unaware that sampling waste from 1993 V-Tank sampling analysis remained stored at ICPP-1617. Thus the laboratories did not communicate the PCB information they now had to the storage facility, to the SAP writers, or to the samplers. Consequently, wastes generated during the sampling activities (i.e., PPE and noncellulose towels) were not segregated from other wastes of the same type at ICPP and were not handled as PCB contaminated. One of the samplers who conducted this sampling activity indicated that he thought these wastes would have been disposed of as mixed (those which came in contact with sampled solutions) and radiation only (those which did not come in contact with sampled solutions). He also indicated that this waste may have been sent to WERF for incineration. The IRT was unable to track this issue to resolution during this review.

\section{WERF Ash Waste Stream}

On 6/11/96, a WMA Form was submitted to the ICPP WMA for samples being sent to ICPP ALD laboratories from the WROCNWERF incinerator. This ash was from the incineration of the ICPP high chloride waste stream, including the 1993 sampling analysis wastes, tracked by WROC as WSID 1953 (described above). On 6/18/96, the laboratory accepted an ash sample from WERF for radiological analysis.

On 6/26/96, during a WMA review of this waste stream, the ICPP WMA Coordinator at that time contacted a WROC WGI assigned to interface with the ICPP laboratories, to tell them: (a) that the waste codes associated with these samples were not compatible with ICPP's PEW, and (b) that the codes provided by WROC for this ash included more codes than were on the original waste sent by the ICPP laboratories to WERF for incineration. Interviews indicate the WMA Coordinator was questioning why more codes were applied. WMA notes indicate a WROC WGI responded that the sample waste codes were wrong and requested the codes associated with the original waste.

On 7/17/96, correspondence, including new waste codes for the ash samples, was received from the WROC WGI by the ICPP ALD POC. Per WMA notes, these codes were also not compatible with the PEW. Notes indicate that the WROC WGI recommended to ICPP that they put the waste into an already approved waste stream, WMA 95137.

The new WMA Coordinator (there had been a recent change in coordinators) agreed to putting the waste in the WMA 95137 "high chloride" waste stream, which would not allow for disposal to the PEW, but would allow the waste to be sent to WROC's facility .

On 1/21/97, an Environmental Support person for the ICPP laboratories notified WROC that in reviewing hazardous waste codes assigned by WROC to ash samples from the burn campaign in which the WSID 1953 was disposed, that they had discovered numerous problems: 
ICPP had provided incorrect or incomplete waste codes for this waste when it was shipped to WERF. A typo had been discovered (P106 should have been P104) that identified sodium cyanide as silver cyanide

- A second typo had been identified showing U227 as U027.

Environmental Support personnel who discovered these discrepancies, did not have information indicating that this waste stream was also PCB contaminated. In addition, interviews indicate she had just been informed about ER's determination regarding the applicability of "F listed" waste codes to the VTank wastes (thus making these codes apply to the samples too). It was noted by the IRT that WROC WGI personnel had been interfacing with ICPP and ER personnel regarding assignment of the proper waste codes to this stream since $3 / 12 / 96$, but no documentation that the presence of PCBs was communicated to them, nor had they yet been formally told that $F$ codes should be applied in regards to V-Tanks wastes.

On 1/23/97, WROC responded to the ALD's Environmental Support person at ICPP that the coding corrections being provided after the burning of the waste would cause them to have to make changes to land disposal restrictions (LDR) certifications, waste profiles, their tracking system, and coding on drums.

The IRT determined that though the ICPP WMA had assigned the tracking number to the waste stream, the WMA had never given final approval for this waste stream's disposal. Interviews with the current WMA Coordinator at ICPP indicated that the WMA was not satisfied, when the Waste Stream Approval Form was originally submitted for their review, that all of the appropriate waste codes and PCB levels had been identified for the waste. ICPP's Environmental Protection characterization personnel's file notes indicate that they had identified information regarding the waste source, and felt that the waste may be TSCA regulated and possibly listed. When one employee left the company, and other characterization personnel were relocated to other facilities, this information was not passed on to other Environmental Support personnel supporting the laboratories, though the information was left in their files.

Neither the WMA members, nor the ALD's Environmental Support personnel were aware that the waste had been shipped for disposal until after the fact. The waste was shipped without a final approval from the WMA. Even if they had the information regarding TSCA, the WMA or the Environmental Support personnel supporting the laboratories still would not have known it had gone to WERF for incineration. Environmental Support personnel are not required to sign off any technical approval for waste clisposal. At ICPP this is to be arranged up front through the WMA process.

Records reviewed by the IRT indicate that on 4/14/97, WROC requested that ICPP file an Occurrence Reporting and Processing System (ORPS) report for the waste burned by WERF, WSID 1953. On 4/17/97, an Occurrence Report was written that says waste was shipped from ICPP to WERF, and the waste and shipping documents did not identify the PCB contamination. (Reference Occurrence Report IDLITC-LITCOSITEW-1997-0001)

\section{V-Tank Sampling and Analysis Scenario Including Waste Management}

In March of 1996, the LMITCO's ER Department had the TAN V-9, V-13, and V-14 Tanks sampled. Samples were sent to the ICPP RAL, and to an off-Site Babcock \& Wilcox laboratory.

On 3/23/96, the ICPP RAL POC submitted a form to the WMA requesting waste stream approval for analysis to be conducted on TAN V-13 and V-14 Tank samples. This WMA Form indicated that PCB wastes from this analysis would be generated at a TSCA level and that the residues could be sent to the WROC MWSF. The WMA assigned a tracking number 96061 to this waste stream. On $3 / 25 / 96$, the 
RAL POC submitted a second WMA form requesting waste stream approval for analysis to be conducted on TAN V-9 samples. As with the first form, the WMA Form 96062 indicated that the PCB wastes would be generated at a TSCA level and that the residues could be sent to the WROC MWSF.

The IRT noted the following regarding these sample analyses waste streams:

- The WMA never granted final approval for the disposal of the ICPP WMA 96061 or 96062 waste stream. During interviews, WMA members indicated that the laboratory was granted approval to analyze, but as a type of preliminary approval only. They were not granted approval to dispose of the waste. They were directed to hold the waste until the disposal path was approved by the WMA.. This preliminary approval for analysis only was granted although ICPP procedures forbid the generation of a waste stream before WMA approval.

- ICPP procedures state that generation of a waste stream (thus analysis) may not begin until generators (the ALD) have an approved WMA, unless it is an "emergency" as defined by their procedure, WN-23. However, the WMA allowed the ALD laboratories to analyze before a full approval to meet ER needs. Interviews indicate that "this exception to the rules," allowing for analysis before full approval for disposal, may actually be a common practice with environmental samples now analyzed at ICPP.

Current and past ALD POCs, the ALD manager, as well as the current ICPP WMA Coordinator explained during interviews that the thought pattern of the ICPP ALD, as well as the WMA, has been evolving. As the ALD strives to become an "environmental support" laboratory supporting analysis needs from outside ICPP versus a "process laboratory" supporting only the ICPP facility, they have been considering "rush" needs for environmental samples in the same context as they consider "emergency" needs of the ICPP processes. They explained this has been done to meet sampling timelines and characterization of wastes for rush orders, thus the WMA provides preliminary approval for waste generators during analysis, but the laboratory is directed not to dispose of waste associated with the analysis until the disposal is approved.

As the ICPP procedure for the WMA process has not been revised to reflect this change in philosophy and practice, further problems have resulted in that the laboratories have not always gone back to the WMA to coordinate a final approval for disposal. In fact waste has been shipped from these laboratories for disposal without the WMA's knowledge. Disposal problems associated with this particular waste stream resulting from this failure to follow procedures currently in place are described below in the section written to describe WSID 1971.

- On $2 / 08 / 96$, in working to assist the ICPP laboratories in securing disposal options for waste generated in support of environmental sampling analysis, the ICPP Environmental Support Supervisor, attempted to obtain permission from regulators to dispose of PCB residuals which would comply with the PEW's WAC, in the PEW. The Idaho Department of Environmental Quality (DEQ) meeting minutes, from their meeting with LMITCO on $2 / 08 / 96$, indicate that the LMITCO Supervisor asked the DEQ representative if there was a problem with PCB residuals getting into the liquid waste stream. The minutes indicate that the DEQ representative responded that there was no problem as long as it did not concentrate elsewhere, and that he would double check with the EPA. The LMITCO Supervisor, who had made this request, indicated to the IRT that a final answer from the EPA was not received. 
Therefore, the WMA's instructions were to continue to refuse permission to dispose of PCB wastes regardless of the concentrations in the PEW.

ICPP personnel interviewed said, and documentation indicated, that the ICPP ALD POC, as well as Environmental Support characterization personnel supporting the ALD, contacted numerous other company personnel in an effort to obtain the proper characterization information needed to ensure proper disposal of the 1996 waste. They contacted the original generators, ER, personnel responsible for the TAN V-Tanks, and the Environmental Compliance TSCA Subject Matter Expert (SME). ALD personnel and Environmental Support assigned to assist the laboratory said that they were not readily provided the information requested from ER and that it appeared that ER personnel may have been confused and did not understand why they needed it.

On 12/05/95, the ICPP ALD POC wrote ER personnel responsible for the TAN V-Tanks asking if the tanks had TSCA levels of PCBs in them. ER personnel responded that the tank was not TSCA regulated. On that same day, the LMITCO Environmental Compliance SME assigned to oversee CERCLA activities at the INEEL, who had seen a copy of this request by the POC for information, responded to the POC that a "substantial amount of PCB oil was taken from the V-2 Tank." ER personnel who received copies of that response followed up on 12/10/95 with a note to the POC agreeing with the environmental compliance call of the CERCLA SME.

In December 1995, a request was made to ER by the ALD POC for additional characterization information in his effort to ensure the proper management and disposal of analysis wastes that had been left over from 1993, and which were still stored at the laboratory. This additional waste separated from the other 1993 waste awaiting shipment for disposal and (described in this report under WSID 1953), was being worked by the POC before his 3/20/96 submittal of a WMA Form for its disposal (WMA 95127). Even though this request was made in December of 1995, just before the April 1996 shipment of the rest of the 1993 sampling waste stored at ICPP, the laboratory POC was not aware of the first batch of waste, nor that it was being stored at ICPP. The reasons for this lack of awareness were (a) the POC at this time was not the same POC who supported the laboratory during the 1993 timeframe, and (b) the batch of waste was not stored at the laboratory, rather it was stored at another ICPP facility, ICPP-1617.

On 2/21/96, the LMITCO Environmental Compliance TSCA SME responded to a technical question proposed by a WROC WGI who was working with the ICPP ALD POC regarding whether analytical residuals from the V-Tank samples were TSCA regulated or not. In his response he explained that oil removed from the V-2 Tank had a PCB concentration of $680 \mathrm{ppm}$ in it, and that if the tanks were interconnected then the samples and analytical residues from each of the tanks would also have to be handled as TSCA waste and would carry the $680 \mathrm{ppm}$ concentration. He also explained that CERCLA may be able to get some relief from the TSCA level of $680 \mathrm{ppm}$ carrying to the wastes in each of the tanks. However, it appears that the WROC WGIs did not know that the ER Department had never approached the regulators in an effort to get relief under CERCLA from managing all V-Tank waste as TSCA regulated at the $680 \mathrm{ppm}$ level nor at that time did they have plans to do that. This was also not understood by the ICPP ALD laboratory POC. During interviews with him, he said he thought this response meant the laboratory wastes may be able to be managed as PCBs below TSCA levels, thus managed at levels as found in the analysis.

On 2/21/96, a WROC WGI wrote the ICPP ALD POC indicating that he understood the laboratory's waste from this stream needed to be managed as TSCA waste. The WROC WGI also said that he would like to have the waste that was actually $<5 \mathrm{ppm}$ PCBs segregated from that which was $>5$ pprn PCBs in case a future ROD allows some relief from TSCA. 
The Environmental Compliance TSCA SME for the company indicated that what he meant in his response to the requests for information was that the EPA could grant relief from the $680 \mathrm{ppm}$ and allowed the site to manage the V-Tank waste at a PCB level as found within each tank. He indicated that he did not intend that to be interpreted to mean the waste management relief would apply to the actual PCB levels of the sample analysis wastes after dilution. For clarification, these waste streams in consideration had PCB leveis on samples analyzed of $29 \mathrm{ppm}$ for V-13 Tank and $.036 \mathrm{ppm}$ for V-9 Tank. However, sludge samples from the same tanks analyzed at an off-Site laboratory indicated $11 \mathrm{ppm}$ for V-13 Tank and 310 ppm for V-9 Tank, which is well above the limit triggering TSCA applicability. The information regarding these PCB concentrations of $11 \mathrm{ppm}$ and $310 \mathrm{ppm}$ were not made available to either the ALD POC or to the WROC WGI, nor were they aware additional samples had been sent off-site.

The Company Environmental Compliance SME for CERCLA, when interviewed clarified that this relief in managing PCBs at concentrations as found is generally only given when the source of the PCBs is unknown. He said he does not believe that would apply to the V-Tank systems PCBs, as a leaking crane that operated in the TAN Hot Shop is the suspected source. Again, he clarified this would have to be negotiated.

On 7/15/96, analytical residuals from two V-Tank samples were washed down the ALD drain to the ICPP PEW as noted in the Satellite Accumulation Area (SAA) log. These two samples (V-13 Tank sample 9605022 and V-9 Tank sample 960422) had been combined in analysis and fused at approximately $1,000^{\circ} \mathrm{F}$ for 1 hour. The V-13 Tank sample was reported to be a 1-gram sample and the V-9 Tank sample was reported to be 1.5 grams. The PCB concentration for the V-13 samples was $29 \mathrm{ppm}$ and the concentration for the V-9 sample was $.036 \mathrm{ppm}$. The ALD POC indicated that even though he knew PCBs were not to be disposed to the PEW, he thought the PCBs were destroyed in analysis and were no longer present. Therefore, he instructed the laboratory technician to dispose of the PCBs in this manner, though he acknowledged that the WMA had directed him that this not be done.

On 10/03/96, the laboratory analysis wastes, including rinsates and wash waters, were placed in three containers and shipped to the WERF incinerator. Before shipment, WROC personnel assigned a Waste Stream ID Number to this waste stream of WSID 1971 for their tracking purposes (further described below). The waste was rejected by WROC and returned to ICPP where it remains in storage and is being managed as TSCA waste.

\section{V-Tank Analytical Wastes WSID 1971}

Some of the following information used to describe the history of this waste stream is similar to that described above for the 1993 sampling scenario and the WSID 1953. It has been added here to add clarity to the report and to aid readers following the events associated with the individual streams.

This waste stream also originated with the TAN V-Tanks. ER was the original generator with the ICPP ALD becoming a secondary generator (see above 1996 V-Tank sampling analysis scenario and the 1993 sampling scenario). Described on WROC documentation as "analytical laboratory debris and extraction dissolution fluids from sampling of the V-Tanks," this stream originates with the 1995/96 sampling of the V-Tanks (V-1, V-2, V-3, V-9, and V-13). This stream also contains some residuals from the 1993 sampling analysis.

An ICPP form, ICPP-5652, Request for Hazardous Material/Hazardous Waste Shipment, completed before shipping this waste to WERF, indicates there are PCBs in this waste at a concentration of $680 \mathrm{ppm}$. However, the 5/14/96 LDR Notification does not indicate PCBs, nor does the Uniform Hazardous Waste 
Manifest of the L-0669. Though the LDR Notification Form was not correct, notes included in WROC's files for this waste indicate that the WGI working with the ALD POC before the shipment was aware of the PCBs, and that the V-Tanks had PCBs of 680 ppm.

The ICPP WMA assigned tracking numbers allowing generation of the waste streams for the 1996 sample analysis, but they never granted final approval for disposal of the waste associated with these streams. They also assigned a tracking number to the wastes from the 1993 sampling analysis, which were still in the laboratories, of WMA 95127, but did not provide final approval for the disposal of this waste either.

On 1/12/95, while working to help the laboratory ensure proper characterization of the TAN V-Tank sample wastes being generated in support of the sampling efforts, ICPP Environmental Support characterization personnel questioned whether there were RCRA waste codes associated with the V-Tanks (reference WMA files). Notes indicate that they contacted the ER department (the generator) to obtain ER's characterization information (i.e., the PCB concentration level that should have been assigned). During interviews with ICPP personnel, they said they were not readily provided the information requested. Though the January 1995 notes were in regards to 1993 waste issues, other notes in the files indicate that in 1996, ICPP characterization personnel were still trying to resolve TAN V-Tank characterization issues. The 1996 work was being done to determine the proper codes that would be associated with V-Tank sample waste before the laboratories accepting anymore ER samples for analysis.

In December of 1995, a request was made to ER by the ALD POC for proper characterization information for part of this waste stream (that which was generated in the 1993 TAN V-Tank sampling analysis). This 1993 analysis waste was additional and had been kept segregated from other waste generated in the 1993 analysis which, at that time, was stored and awaiting shipment for disposal in ICPP1617 (reference WSID 1953).

On 3/20/96, the ALD POC submitted a form to the ICPP WMA for disposal approval, and the WMA assigned tracking number WMA 95127 to the 1993 sampling analysis wastes. The POC in 1996 was not aware of the stored 1993 waste associated with the same waste he was working to characterize. (reference WSID 1953 above).

On 2/21/96, the LMITCO Environmental Compliance TSCA SME responded to a technical question proposed by a WROC WGI regarding what the proper PCB concentration level would be for sample residuals from V-Tank samples. This response clarified that the concentration level of $680 \mathrm{ppm}$ PCBs would apply. (Reference 1996 sampling analysis scenario above).

On 4/10/96, the ALD manager signed a Form 669 , Material and Waste Characterization Generator's Certification Information, prepared by an Environmental Support characterization person working with this ALD at the time. This form submitted to shipping before the preparation of a Uniform Hazardous Waste Manifest and shipping of the waste to the disposal facility, clearly stated a PCB concentration of $680 \mathrm{ppm}$. Files indicate that this form was redone on a Form L-0435, which replaced the 669 Form, on 9/25/96. This redone form was later approved by a WROC WGI on 10/03/96. In redoing the form, the $680 \mathrm{ppm}$ concentration was left out of Section $2 \mathrm{a}$ of the form where it was indicated on the first form, but included in Section 2b, Chemical Characteristics of the Material.

On 5/21/96, a WROC WGI sent a request to the ICPP ALD POC for historical information regarding the history of the PCBs in this waste stream. On 5/22/96, the POC responded sending information to WROC WGIs that indicates that he had been working with the ER Project Managers 
(original generators of the samples) and the LMITCO TSCA SME to try and resolve the characterization issues.

On 10/03/96, as stated above, a WROC WGI who was assigned to work with the ICPP laboratories at that time, approved the Form L-0435 indicating that the PCB content of this waste stream was of a TSCA regulated level of $680 \mathrm{ppm}$.

The current ICPP ALD POC shipped the WSID 1971 waste to WROC on 10/10/96 after having resolved all issues he was aware of, except what PCB level would be assigned to the waste. He said he could not get an agreement between the WROC WGI, the original generator (ER), and the ICPP Environmental Support personnel to determine what the PCB concentration level should be. Other interviews also indicated that the POC, the ICPP WMA Coordinator, and the laboratory's Environmental Support person all went with the waste to WROC to resolve the PCB concentration issue. The WMA Coordinator indicated that based on ICPP characterization personnel's research, $680 \mathrm{ppm}$ would apply.

On 10/10/96, WROC rejected the WSID 1971 waste and it was shipped back to ICPP ALD laboratories and placed in TSCA storage in ICPP-602, Room 224. Per the ICPP personnel who traveled with the waste to WROC to resolve the concentration issues, WROC requested that ICPP now sample the individual drums and determine the concentration of the PCBs currently in the drums. A followup note from the WROC WGI said the reason for the rejection was that "(1) there is substantial indication that PCB-related analyses for the waste are not yet complete and (2) the waste has a potential of being TSCA related." ICPP personnel interviewed (the current POC, the current WMA Coordinator and the Environmental Support person assigned to the laboratory) said that this note further confused them, as the paper trail clearly indicated PCBs before shipment as well as the TSCA issue, and that WROC personnel were aware of TSCA levels of PCBs associated with the waste.

\section{Other PCB Characterization and Waste Management Issues Identified}

The IRT identified other examples of a failure to apply TSCA requirements to PCB wastes generated at the INEEL. A note dated 4/15/96 was found in WROC's files for the WSID 1971 waste stream regarding concrete samples from OU 1-10, TAN TSF-21 Valve Box. These samples were being sent to ICPP for analysis at that time (reference WMA-96159). This note provides direction to the laboratory from a WROC WGI which would, if followed, have caused the laboratory to incorporate additional TSCA regulated waste to be mixed with other waste and shipped to WERF for incineration. This note says that "as long as the PCB levels were $<5 \mathrm{ppm}$, then this waste would fit into the scope of the high-chloride waste stream that is treated at WERF."

The TSF-21 Valve Pit is part of the TAN V-Tank system and should be regulated at $680 \mathrm{ppm}$ to comply with TSCA. The WGI was not available for interview, but in other interviews ICPP personnel stated that they were not made aware that the TSF-21 Valve Pit was associated with the TAN V-Tank system, and neither they nor the WGI understood that the $680 \mathrm{ppm}$ concentration would also apply to this sampling waste.

\section{PPE Waste Management at ER Activities}

To manage the resources and work needed to complete sampling of an operable unit, a Waste Area Group (WAG) manager assigns a field team leader. The current WAG-1 manager indicated he would expect the field team leader to conduct the sampling operations and to handle the generated waste in accordance with the SAP. 
The field team leader is expected to interface with ER and facility personnel as needed to accomplish the sampling activities. The field team leader may be the author of the SAP, or the SAP may have been written for them. The field team leaders for the 1993 and 1996 sampling events authored the SAP that was used in their evaluations. The field team leader for the 1993 sampling event indicated she had knowledge that PCB contamination had been in the V-Tanks and that was why she added a PCB analysis in the SAP. The field team leader indicated she was moved off to another project soon after the sampling event was completed. She was not aware that the laboratory did not receive the SAP.

In describing the 1993 sampling event, the 1993 field team leader stated that no member of the sampling team entered the tanks. They accomplished the sampling from the access cover. They did not observe any oil in the tanks; not even an oil sheen on the water. She indicated that she remembered that no oil was detected on the wipe down rags used to clean the equipment.

The SAP has a section that describes the waste handling requirements that the field sampling team must follow. The waste generated by the sampling operation may be transferred to the resident facility if it is compatible with that facilities waste streams. That was the practice in the 1993 and 1996 sampling events at the V-Tanks. Sampling wastes were transferred to TANO for management. Information needed for that management was communicated by ER personnel. This transfer of waste management responsibilities is still the practice. However, since April of 1997, a written hazardous waste determination is created to ensure better and documented transfer of waste management information. The 1993 sampling field team leader stated she left the PPE and other waste materials in plastic bags within the contamination area at the V-Tanks. The PPE and other wastes generated during the sampling the V-Tanks in 1993 was included in the TAN low-level radioactive waste stream.

The 1996 field team leader is currently employed full time by the ER directorate. This field team leader wrote Revision 1 of the SAP associated with that sampling activity. The 1996 field team leader stated that she had heard that that the oil removed from the V-Tanks had a PCB concentration of $680 \mathrm{ppm}$, but could not remember where she had heard that. Interviews indicated that she did not document reviews to confirm if this information was or was not true. The field team leader stated she was surprised at the PCBs levels when the analysis was returned for the V-Tank samples. She stated she would not know if a tank was TSCA regulated unless told. The 1996 SAP specified samples were to be taken for PCBs.

The 1996 SAP stated the waste was to be handled as low-level radioactive waste. As with the 1993 waste, the 1996 sampling wastes were turned over to TANO to manage based on information provided to them by ER personnel. The current ES\&H Compliance Officer for ER indicated to the IRT that he believed that there would not be an issue with PCBs in the V-Tanks in 1996, because the oil with the PCBs was removed. This compliance officer was not associated with the 1993 sampling event. The compliance officer stated he became aware of PCBs in the V-Tanks when he reviewed the Field Sampling Plan for OU 1-10 (INEL - 95/0304, Rev. 1). He also stated he remembered talking about historical information about P'CBs being in the V-Tanks per conversations with the EA CERCLA SME in the fall of 1996, but at that time that did not trigger him in regards to the current situation.

Though the ER library had information filed there indicating that oil found in the V-2 Tank was determined in the 1980-81 timeframe to have a PCB concentration of $680 \mathrm{ppm}$, the actual, as found, levels of PCBs in the V-1, V-2, V-3, V-9, V-13, and V-14 Tanks were unknown to the ER organization until the return of the 1996 sample analysis results. The sample results for the $1996 \mathrm{~V}$-Tank samples are as follows: 


$\begin{array}{llc}\text { Tank } & \text { Water Phase } & \text { Sludge Phase } \\ \text { V-1 } & <0.1 \mathrm{ppm} & 660 \mathrm{ppm} \\ \text { V-2 } & <0.1 \mathrm{ppm} & 260 \mathrm{ppm} \\ \text { V-3 } & <0.1 \mathrm{ppm} & 400 \mathrm{ppm} \\ \text { V-9 } & 0.036 \mathrm{ppm} & 310 \mathrm{ppm} \\ \text { V-13 } & 29 \mathrm{ppm} & 11 \mathrm{ppm} \\ \text { V-14 } & - & -\end{array}$

Before the 1996 Consent Order, the V-Tank and its associated systems were "declared" not to contain F listed hazardous wastes. The ROD 1-07B specifically states that the process knowledge was not sufficient to categorize the wastes as listed based solely on the organic solvents found in it. After wastes were analyzed in the TSF-21 Valve Pit (part of the V-Tank system), a listed waste determination was issued by ER. The waste in the V-Tanks was determined to also be F-listed hazardous waste after the TSF-21 Valve Pit determination was made.

Based on the now assigned F-listed codes, and his realization that the tanks were PCB contaminated, the ER ES\&H Compliance Officer stated he determined the PPE waste generated in the 1993 and 1996 sampling events should have been controlled as PCB listed-mixed waste. During interviews with the IRT, he stated he now believes in general, PPE from other tanks measurement activities were managed incorrectly as low-level radioactive waste instead of PCB mixed or PCB listed-mixed waste.

The 1993 and 1996 V-Tank sampling PPE were mixed by TANO personnel with other radioactive contaminated PPE generated during regular TAN operations. This waste was placed in cargo containers and shipped to WERF for incineration. After the ER ES\&H Compliance Officer discovered the inappropriate management of this waste, he issued an ORPS (ID-LITC-WERF-1997-0004). The mismanaged waste was returned to TAN. The cargo containers are currently stored at the TAN RPSSA. They have been marked to indicate the contents are PCB Mixed LLW materials.

\section{Environmental Restoration (ER)}

This section is written to clarify the roles and responsibilities associated with the LMITCO ER organization's management of INEEL CERCLA sites. During the 1980s, D\&D and ER activities associated with these tanks were under the auspices of EG\&G Idaho, as they were in 1993. Since October of 1994, the ER organization has been managed under the LMITCO contract.

Currently, CERCLA sites at the INEEL are divided up by specific areas called WAGs. WAG-1 is the area where the TAN V-Tank system is located. The WAG manager (i.e., Project Manager) is fully responsible for the conduct of operations, technical issues, scope, schedule, and costs associated with an assigned WAG. The current WAG-1 manager has been employed in environmental restoration for 4 years. The WAG-1 manager is responsible for all of TAN.

Although there are numerous personnel working in the ER Department, the WAG manager must often obtain resources from within LMITCO or subcontractors to perform technical, remedial, sampling, and waste management tasks. If they have a compliance issue or a problem they need assistance with, they may contact Environmental Affairs (EA) for assistance. The current WAG-1 manager told the IRT members that they need more assistance with compliance, and that they have asked for it in the past. They 
would like additional EA resources to be available on a routine basis and be located with the ER organization supporting them full time.

During interviews with the IRT, the ER ES\&H Compliance Officer discussed the management of the TAN Injection Well, which is located at the end of the Intermediate Level Waste System at TAN, which includes the V-Tank. He stated his concerns with the sludge that has been removed from the injection well during past remediation activities and the potential for PCBs associated with the sludge. That sludge was packaged and is in storage at the MWSF. The Remedial Investigation Final Report with Addenda for the Test Area North Groundwater Operable Unit 1-07B at the Idaho National Engineering Laboratory, Volume 1, EGG-ER-10643, January 1994, does not indicate the sludge from the bottom of the TAN Injection Well was analyzed for PCB contamination. The same report shows the water from the injection well was below detection levels for PCB contamination.

The ER organization has established the Environmental Restoration Review Committee (ERRC) to review ER documents. The committee is comprised of these ER personnel: WAG managers, the ES\&H Compliance Officer, quality assurance personnel, and other technical personnel as needed. An Environmental Affairs person is not a member of this review committee. The ERRC is responsible for reviewing ER SAPs, remedial investigations documents, feasibility studies documents, health and safety plans, remedial designs, RODs, and other technical documents. This committee did review documentation associated with the $1996 \mathrm{~V}$-Tank sampling activities before commencement of those activities. The ES\&H Compliance Officer stated that this committee did not realize at the time of this review that PCBs had been identified in the past in the V-Tank waste.

In interviewing the CERCLA SME in EA to determine his association with the ER organization, he stated the roles and responsibilities for EA are not clearly defined or documented. He also said his current relationship with ER directorate is ad hoc.

\section{Sample Management Facts}

This section is written to clarify the roles and responsibilities associated with the management of samples generated at the INEEL. Before October 1994, those activities associated with sampling of the V-Tanks were done under the auspices of EG\&G Idaho. Samples that were processed at the TRA RML were also done under the EG\&G Idaho contract. Those processed at the ICPP laboratories were under the WINCO contract. Since October 1994, all of these activities have been managed under the LMTTCO contract, including disposal of sampling wastes and analysis wastes.

A new LMITCO Management Control Procedure (MCP)-2864, Sample Management, Rev. 0, addresses handling and controlling samples and associated documentation submitted for chemical, physical, and/or radiological services. It provides sample submittal instructions for the sample generator, and handling and tracking instructions for on-Site laboratory personnel. It also provides return and disposition instructions for the sample generator and on-Site laboratory personnel. This procedure applies to all samples submitted to on-Site laboratories and to samples returned from off-Site locations. This procedure was not in effect at the time of either the 1993 or 1996 V-Tank sampling activities.

Per MCP-2864, the sample generator is responsible for completion of INEEL Form L-0435.26\# or equivalent. Generators of all INEEL samples must complete this form, which is submitted to either the SMO or, if the SMO is not used by the generator, to the laboratory. The SMO forwards the information, if applicable, to the laboratories. Though this procedure has been in effect for several weeks, the IRT noted 
that on 5/12/97, the SMO submitted a TOS 695 to the ICPP laboratories without the information required by MCP-2864.

LMTCO MCP-242, Obtaining Laboratory Services for Environmental Management Funded Activities, Rev. 3, requires persons submitting environmental samples for analysis to use the LMITCO SMO. This procedure is applicable to all EM-funded sample activities with the following exemptions: (a) the transuranic waste characterization program, and (b) process control activities at ICPP. Specific exemptions are also made for industrial hygiene samples and development samples taken for analysis at the Applied Engineering Developmental Laboratory (AEDL) (ICPP laboratories). It is not required to process these samples through the SMO. However, MCP-242 does not address this exception. MCP-227, Sampling and Analysis Process for Environmental Management Funded Activities, Rev. 5, contains language similar to MCP-242 regarding specific exemptions for EM-funded work. The procedure also consists of two appendices, Appendix D and E, which are required to be completed by the ER field team leader or project coordinator. These appendices are meant to provide full disclosure of any waste characterization information, or process knowledge information that will determine how altered and unaltered samples will be dispositioned. Neither of these procedures were in effect at the time of the 1993 or 1996 sampling activities.

Currently, the LMITCO EA organization reviews the requisitions for analytical services to determine if approved laboratories are being used for EM-funded analyses, though approved laboratories are not required for other analysis. EA performs vendor audits of off-Site laboratories that have been selected to perform analysis for LMITCO as required by MCP-243. This procedure only applies to EM-funded activities. The vendor audit scope includes a review of quality, waste management, and recordkeeping practices as well as procedures. EA personnel interviewed said that LMITCO on-Site laboratories are not audited in the same fashion as off-Site laboratories.

To better control the management of waste generated by analysis of LMITCO samples at off-Site laboratories, the current SMO Manager stated that awarded subcontracts for off-Site analytical laboratories were recently revised to include language requiring the laboratories to take responsibility for all waste disposal.

An EA engineer stated the ICPP laboratories are not in compliance with Occupational Safety and Health Administration (OSHA) 1910.1450, which requires a laboratory to have a Chemical Hygiene Plan (CHP). A suggested element of the CHP is a section for discussion of the laboratory's handling of waste, commonly referred to as a "Waste Management Plan." During an interview with the laboratory manager on 5/13/97, he stated that there was no document for the laboratory called a Waste Management Plan, but that several MCPs gave detailed instructions for management of wastes in the laboratory. These MCPs are $442,443,444$, and 453 . In a later interview with the manager, he revealed the CHP is contained in an AEDL procedure.

The IRT noted that the laboratories used to perform analysis of industrial hygiene samples or bioassay samples collected to determine personnel exposure to radionuclides analysis samples are not required to be included in the EA vendor audit program. These laboratories may generate a hazardous waste while performing the required analytical method without regard to the contaminants in the sample. The levels of radioactive material in bioassay samples are slightly above background and below drinking water standards. The levels of potential hazardous materials in industrial hygiene air samples are very low. The levels of potential hazardous materials may be any quantity for bulk samples. 


\section{ALD Laboratories}

The ALD consists of several laboratories that support operations at the INEEL. Laboratories, under direction of ALD management, are located at the ICPP, TRA, CFA, and the INEEL Research Center (IRC). The various ALD laboratories are engaged in analytical testing services for:

- Routine waste processing activities conducted at ICPP

- Facility support for operations at ICPP and TRA

- Industrial hygiene determination

- Bioassay and dosimeter testing

- ER organization

- Transuranic Waste Characterization Program for WIPP

- Screening samples for SMO for off-Site shipments.

During the last several years, according to the ICPP Laboratory Director, the laboratories associated with the CPP and the TRA facilities have been evolving from process control and support laboratories to laboratories capable of supporting regulatory determinations for CERCLA, RCRA, and other EPA requirements.

The ALD Laboratory Director stated the major funding for the ICPP laboratories is supplied by Nuclear Operations at ICPP, (approximately 60\%) and by the TWCP project from WIPP, (approximately 30 to $33 \%$ ). The balance of funding comes from "emergency" situations, which the laboratory handles only if no other alternatives exist.

According to the ALD Laboratory Director, the award of the TWCP contract coincided with a staff reduction, which has resulted in staffing levels that are barely adequate to handle scheduled workload. Compensated and uncompensated overtime is used to maintain turnaround time commitments for work from routine customers. Nonroutine customers are given low priority and/or extremely long lead times for scheduling analysis ( 30 to 60 days). The laboratory is currently hiring additional personnel to support the existing, workload.

Laboratory staffing levels are determined by obtaining funding commitments from each of the analytical users during the fiscal budget planning process, according to the Laboratory Director.

The ICPP Laboratory was awarded a contract to perform analytical services for the TWCP for WIPP in the fall of 1996. Several ICPP laboratory personnel, including the laboratory POC, the Sample Custodian, and the Quality Assurance Officer, stated that the TWCP required the laboratory to make changes to its operations to satisfy customer requirements. Examples of these changes are a projectspecific quality assurance plan, sample receipt documentation checklists, project-specific analytical procedures written to satisfy the regulatory requirements of the customer, project-specific forms and reports, participation in the customer's performance evaluation program, and training and documentation to qualify laboratory personnel. 
The laboratory was audited by the WIPP office in early 1997 for compliance with the TWCP SOW. One finding was identified as a result of the audit. This finding was related to software control and documentation.

A Vendor Assessment was performed by the SMO on $02 / 13 / 97$ for the radioanalytical and radiochemistry portions of the laboratories at ICPP and TRA. The basis of the assessment was INEL95/039, "Idaho National Engineering Laboratory Sample Management Office Statement of Work for Radionuclide Analysis," also called ER-SOW-163, dated February 1995. Ten findings and 20 concerns were identified as a result of the assessment. The findings and concerns were related to the overall Quality Assurance Program, the requirements of EPA's Good Automated Laboratory Practices for electronic data management, and quality issues in the radioanalytical/radiochemistry process.

The laboratory participates in various blind performance evaluation studies. These studies are EPAWater Pollution, DOE-Mixed Analyte Performance Evaluation Program, DOE-Environmental Measurements Laboratory; and EPA-Las Vegas Radiochemistry. Recent performance for all these programs was above average, based on information supplied by the Quality Assurance Officer.

The laboratory also analyzes blind performance samples for the WIPP project. The laboratory received a score in the low 90 s from the most recent sample set.

The ICPP Laboratory Director stated that the high levels of radioactivity and/or the uniqueness of the sample matrix allows the laboratory to deviate from regulatory protocols. The ICPP Laboratory Director also stated that an independent contractor had reviewed ICPP's analytical protocols and supported the deviations made by the laboratory for high-level radiation samples.

The data produced by the ICPP laboratories as a result of the 1993 V-Tank sampling were rejected by the data validation subcontractor hired by INEEL. The validator evaluated the data against INEEL's SOW and regulatory requirements.

Samples for volatile analysis are not segregated from other samples in the Sample Receipt Laboratory. Samples for volatile analysis are stored in the same refrigerator as the volatile standards in the Volatile Organics Laboratory.

The ICPP Laboratory Director and the ICPP Laboratory POC both stated the current methodologies for obtaining approval from the WMA to generate waste as a result of analyzing unknown samples presents a significant burden for the sample generator as well as the laboratory. On May 12, 1997, the laboratory issued an Interdepartmental Communication (Document \#97PCB200AA0014) that detailed the laboratory's responsibility to obtain all the information required by MCPs. Without the required information, the laboratory cannot accept any samples.

According to the ICPP Laboratory POC, delays in turnaround time are created when the required waste management information is not submitted with the sample. The Laboratory Information Management System (LIMS) does not contain any field to record a customer's requested turnaround time or sample due date. 


\section{Laboratory Handling of V-Tank Samples and Waste}

This section has been included to clarify roles and responsibilities in managing samples and analysis wastes at laboratories where INEEL samples are processed. Also included is clarification information associated with that management in relation to the 1993 and 1996 TAN V-Tank sampling analysis.

JDuring interviews with the IRT, the point of contact (POC) responsible for the ICPP ALD in 1993 stated the general practice at that time was to dispose of sample wastes in the PEW. He stated he was encouraged to use the PEW at that time. During interviews with this POC, he said that since that time things have changed. The PEW is now "protected" from additional waste codes being added to the system. He stated that the ICPP WMA is not likely to accept new waste codes in the PEW. The 1993 POC also indicated that the disposal of some of the 1993 sample wastes in the RAL drains that eventually lead to the PEW was common practice at the time. Some of the 1993 wastes were collected due to the high chloride content or for future analysis before disposal. This was done at that time as the high chloride waste stream is not compatible with the PEW WAC.

Since 1993, another ALD employee has taken over the ICPP ALD POC duties. During interviews with the IRT, this POC indicated that all of the 1996 laboratory wastes generated in analyzing the 1996 TAN V-Tank samples were collected due to the unknown nature of the waste. The waste was managed as PCB mixed waste after the analysis was completed.

An off-Site laboratory managed by Babcock and Wilcox also received samples from the 1996 sampling of the TAN V-Tanks. Per this laboratory, the wastes generated in these analysis were collected, rather than disposed, due to the unknown nature of the waste. This laboratory was aware of the TSCA levels of PCBs associated with these samples, as samples sent to them for PCB analysis indicated PCBs in a range from 11 to $660 \mathrm{ppm}$. The residual sample material and sample analysis waste will be returned to LMITCO.

In reviewing information submitted to them regarding the generation of the sample analysis wastes stream created in support of the 1996 sampling activities, the ICPP WMA directed the ALD that all 1996 sample wastes were to be collected and placed in one location. They also directed that none of these wastes were to be disposed of to the PEW because of the PCBs associated with the samples. During interviews conducted by the IRT, the ALD POC stated he understood that direction.

All of the ICPP laboratory sample wastes for the 1996 sampling event, except for two small samples, were collected due to the unknown nature of the waste. The collected sample waste is in a TAA in Room 224 of ICPP-602. The two small samples were disposed of down the drains that eventually go to the PEW (reference the 1996 sampling event described above). The laboratory POC specifically authorized the chemist to dispose of the two 1996 sample wastes in the drain that eventually is to go to the PEW. He stated that he believed the analytical method, a lithium borate fusion analysis, would destroy all organics, including PCBs. He stated that in retrospect that disposing of the samples in the PEW may not have been the right procedure. The ICPP ALD manager was aware of the two 1996 samples that were disposed in the PEW.

The ICPP laboratory uses a computerized database system to control the sample analysis process. The database is central to the control and data collection processes. The database has not been used to communicate sample disposition, although the database could be used to communicate waste and sample disposition information. The ALD POC stated he instructs chemists on waste handling procedures using labels, computer logs, and word of mouth. 
The ICPP ALD manager told the IRT that he believes the WMA works if protecting the PEW is the goal. However, the POC who interfaces between the WMA, the laboratories, the Transportation and Shipping Department, and the WGIs at WROC, said he does not believe the WMA works if the goal is to have the laboratories perform analysis of unknowns to determine the waste characteristics. He said he feels the WMA personnel really attempt to work the system to everyone's benefit, and that they try very hard to meet the needs of everyone and they also feel that the RNEEL system and process is too complicated. He feels he must have an identified place to dispose of the waste before he knows what the material is, thus he can not accept samples that are not fully characterized for analysis-obviously defeating the purpose of analysis in the first place. The laboratory POC stated that he feels the WMA process is tedious.

Waste generated at the ICPP laboratories is stored in RCRA regulated, 90-day storage areas before being shipped to a permitted storage area or a disposal facility. Those areas are called TAAs. During the 1996 September - October timeframe, management problems associated with management of wastes disposed of in the laboratories' TAAs were evaluated. Notes in the WMA files indicate the following:

On 9/11/96, an employee identified as "A. C." documented problems identified with laboratory wastes being disposed of in the ICPP TAAs. In this document he also summarized what appeared to be the contributing facts associated with the waste characterization problems in the laboratories.

- The primary reason they indicated laboratory personnel responsible for the TAAs did not have waste properly characterized was that the laboratory's Project Managers (known to the IRT as the POC) were not communicating to laboratory personnel the characterization information that she had before receipt of the samples.

- The second reason, they indicated they felt laboratory personnel responsible for the TAAs did not have waste properly characterized, was that laboratory personnel generating the waste had a lack of understanding of the RCRA regulations pertaining to waste. They expressed a need for training of laboratory personnel regarding their responsibilities involved in the generation of hazardous and mixed waste. (Reference WMA 96062 files).

- The EA Environmental Support personnel responsible for this laboratory also sent a note to the laboratory manager informing him that laboratory personnel in the ICPP Analytical Chemistry Laboratories were not properly characterizing their laboratory wastes. Specifically, waste codes associated with the source of the samples being analyzed were not being applied to the sample analysis waste. Environmental Support requested that the laboratories segregate waste from analysis conducted on samples sent to the laboratories from outside ICPP from analysis of ICPP samples. This documentation indicated that their conclusion was that laboratory personnel understood the waste codes associated with the production process of ICPP, but not for anything sent to them from outside the facility. (Reference WMA 96062 files).

\section{ICPP Waste Management Process and Systems}

This section of the report has been included to clarify the roles and responsibilities of various organizations at ICPP in the chain of laboratory waste management.

Per ICPP procedures, before the generation of a waste stream (e.g., sampling analysis), the ICPP laboratory POC submits information regarding the proposed stream to the ICPP WMA. The WMA evaluates the proposed waste stream to determine controls needed, adequacy of available characterization information, compatibility of the waste with the ICPP waste handling systems, and other disposal options. 
The WMA process at ICPP has been used since 1993. The ICPP has issued an area-specific procedure that specifies the WMA process. This process also evaluates for pollution prevention opportunities in addition to waste stream approvals. The WMA evaluates the disposal options based on the acceptance criteria of the accepting facility. The WMA has little association with the process once a waste is generated.

During interviews with the IRT, the current WMA Chairman indicated when compliance issues were discovered by the WMA he would report those to the Environmental Supervisor at ICPP. He said he believes they (i.e., the WMA) are an extension of the Environmental Affairs organization at ICPP. He also said he believes they are a mostly RCRA cognizant group, and are not that familiar with TSCA. He stated a PCB risk assessment has not been performed for the PEW.

Documents reviewed by the IRT indicated that in at least one case in 1993, a V-Tank sample was accepted and disposed of before the WMA had approved the waste stream. When the WMA Coordinator was interviewed regarding this issue, he clarified that more than one case has happened where waste was disposed of before the disposal being approved by the WMA. As described in the 1996 V-Tank Sampling Scenario Section above, ICPP personnel interviewed explained this "rush" order philosophy in managing environmental samples, in the same manner as the facility use to manage "emergency" samples. In interviews with the past ICPP Environmental Affairs Support Supervisor, who had worked in the envirorumental department at ICPP for several years, he indicated personnel have tried to rush a hazardous waste determination through the ICPP WMA with incomplete data several times in the past. This he said put great pressure on the WMA, and at times created an atmosphere of animosity as the WMA refused to approve waste streams without adequate documentation.

The ICPP PEW system (see Figure 4) collects wastes pumped from laboratory tanks at the ICPP. The PEW system has an evaporator included in the system. Following the evaporator process, the PEW discharges liquid into the high-level waste tank farm. The ICPP New Waste Calcining Facility (NWCF) feeds its calciner from this tank farm. Those interviewed said that the WAC has been in place for the PEW as long as they could remember. The current WAC for the PEW is in Program Requirements Document (PRD)-166. The official limit for PCBs is $<50 \mathrm{ppm}$. The unofficial limit enforced by ICPP personnel is no PCBs. PRD-166 has replaced PO-40.

An NWCF engineer acts as the "gatekeeper" for the PEW to ensure only liquids meeting the criteria in PRD-166 are allowed into the system. This engineer is a member of the WMA at ICPP and specializes in evaluating waste proposed to be disposed of in this system. This engineer told the IRT members that oil is not allowed in the PEW, and is excluded for criticality control purposes, as uranium concentrates in organic material such as oil and could cause a criticality in the system. The ICPP had accepted liquid shipments from the TAN Intermediate Liquid Waste System into the PEW periodically until 1985 . Per the WAC, any liquids that had oils associated with them had to be rejected, as was the case with the 1981 V-Tank oils.

\section{Environmental Affairs (EA)}

This section is included in this report to clarify the roles and responsibility of EA personnel in the management of samples and of waste generated at the INEEL. During the 1980s, there was not an organization that conducted those functions now managed by LMITCO's EA organization. During the 1993 sampling scenario, EG\&G Idaho had an organization called Environmental Technical Support and WINCO had one called Environmental Protection. Though neither of these organizations have had in the past, nor do they now have uitimate responsibility for management of samples or wastes, they were and 


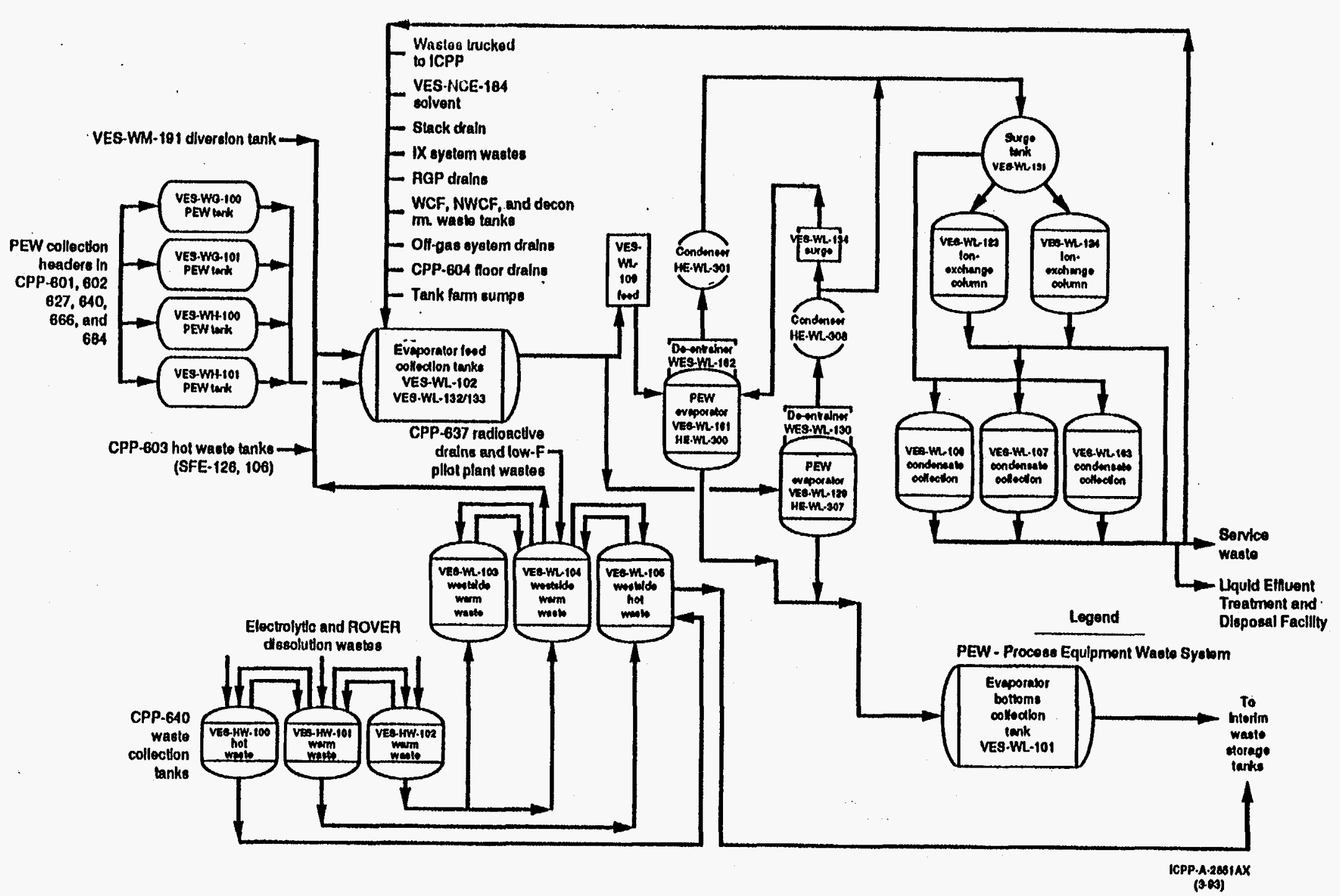

Figure 4. Intermediate-level waste collection system. 
currently are responsible for providing compliance guidance to operations' facilities and the ER organization. The generators have the ultimate responsibility for characterizing and disposing of samples and any resulting wastes from sample analysis. In addition to providing compliance guidance, they were and are responsible for setting company environmental policy, and interpreting regulatory requirements and guidance. This includes generating and maintaining company level procedures directing environmental activities.

Other significant responsibilities of the EA organization are to provide matrixed support to LMITCO organizations for their environmental management needs, and to manage specialty groups such as those that develop and maintain company level environmental reporting documents (e.g., RCRA, SARA, and TSCA reports), and the permitting organizations.

\section{Characterization of Wastes at LMITCO-Managed INEEL Facilities}

Characterization of LMITCO-managed waste is performed by different people in the various organizations (i.e., ER, operations, WROC, and EA). Various environmental personnel interviewed said that characterization is not performed consistently, and that is it is done differently by different people at the INEEL. The current characterization procedures do not specify the qualification required to perform or certify waste characterization. Several EA staff members indicated in interviews that the effort and documentation needed to characterize and move hazardous material through the current system is unnecessarily huge.

Though in their various support roles, many EA personnel do perform this function. Several professional staff members in the EA organization as well as other organizations interviewed by the IRT have expressed concerns about the skill and ability of some persons performing hazardous waste determinations at LMITCO-managed facilities. Those interviewed said there are personnel in various organizations (EA, WROC, and generators too) assigned to perform these tasks who are not able to accomplish a reliable hazardous waste determination. Those interviewed said there are no set criteria for qualifying to characterize waste at the INEEL, and that it would require obtaining supervised training and experience to learn to do it properly.

Several EA persons interviewed expressed the desire to have various disciplines involved in the characterization process. The following disciplines have been suggested: chemists, transportation specialist, waste management personnel, environmental engineers, and generators. They also stated they would like a consistent method and process followed to characterize wastes. In agreement with this, environmental engineers stated it was difficult to characterize ER waste because of "bottlenecks" in the ER SMO process.

A TAN environmental engineer, originally hired into the EG\&G Idaho ER Department, stated that before the October 1994 INEL contract consolidation, he was the only environmental engineer in the ER group. The other ER environmental personnel at that time were project management personnel or were in other technical disciplines. In that capacity, he helped ER characterize their waste. He stated he was not replaced when he left the group. As an Environmental Support person now supporting TAN/SMC activities, he finds he has to help solve characterization problems associated with waste generated by the current ER organization, and left for TANO management. He also indicated that he felt the current characterization and waste management processes through disposal are cumbersome and cost prohibitive. An environmental supervisor at TAN stated that the waste is generated from CERCLA activities and is left in a TAA. He said he felt the wastes are not being actively managed. 
During the IRT's interviews, a Treatment, Storage, and Disposal Facility (TSD) supervisor at TAN stated he interfaces and works with the WROC WGIs assigned to TAN. This supervisor is also a member of the TAN WMA group. He said that characterization personnel working at TAN do not have to interface with the WROC WGIs very often. However, he discussed several cases where a WGI would request additional sampling beyond that needed to do full RCRA required characterization to perform additional characterized of waste- with materials such as paint.

The supervisor expressed his belief that much of the additional characterization was not justified for disposal of waste. He said he felt this was being required to try and dispose of as much waste as possible at the WERF facility. He said that it is often cheaper to send the waste off-Site for disposal with the already adequately performed characterization information, versus trying to meet WERF characterization needs. He described one case where the WGI required they do expensive, additional characterization sampling, and then determined that the waste was not acceptable for WERF incineration, and would have to be sent off-Site anyway.

A health physicist at TRA expressed how radiation characterization data were passed back and forth between he and the WROC WGI assigned to work with him before WROC accepting the waste shipment. He felt some of the data requested by the WGI were valid, however, he felt other data could not be for technical reasons.

EA Environmental Support Supervisors interviewed, who support TRA, had several comments regarding characterization of waste. One stated there has been a lack of adequate characterization data at TRA. He felt the newly formed WMA process put in place at TRA was helping to resolve this problem, which was confirmed by another EA Supervisor. TRA was working to coordinate shipping waste they had to an off-Site disposal facility versus absorbing the characterization costs associated with the sampling costs needed to meet WROC's requirements for disposal at their facilities.

One difference noted by the IRT between how the ICPP WMA process and the TRA WMA process worked regarding characterization of sample analysis wastes was that the samples brought into TRA are not "run through the WMA" before being brought there. Instead, the waste streams the samples are put into are reviewed by the WMA. It was not clear to the IRT as to which process would work the best, however, the bottleneck of not being able to analyze unknowns is resolved by this difference. It should be kept in mind though that the ICPP WMA process currently allows for the analysis of unknowns, it is just not reflected in their procedure (this procedure change need was communicated to the ICPP WMA Coordinator).

An EA engineer discussed with the IRT the evaluation she has been leading of the waste stream management process. Her team has been looking into the weaknesses and lessons learned in pollution prevention efforts, characterization, records, tracking, and disposal.

WROC WGI personnel indicated that they had serious concerns with the characterization of wastes they are required to receive and manage at WROC. They also expressed concerns regarding the qualifications and abilities of personnel who are tasked with characterizing waste across the site.

The project manager of the Non-Incinerable Mixed Waste Treatment Program at WROC stated the program has routinely used the SMO to procure waste characterization services. They have an Analysis Request Form in place for this purpose. This form requests information on the hazardous characteristics of samples that the laboratory may need to know, such as, F-listed components. Waste Operations (WO) provides the information to the SMO as requested on the Analysis Request Form. For treatability study 
samples, WO also provides SMO a copy of a spreadsheet detailing pertinent mixed-waste information. For PCB mixed waste that require characterization (e.g., the consolidated waste streams being prepared for incineration at ORNL's K-25 Incinerator), the Chain-of-Custody document is clearly marked that the samples contain PCBs. The sample container is also marked identifying the contents as containing PCBs (using a label or by writing the letters PCB on the bottle). Radiological information for samples is always provided to the SMO and radiation readings are also placed on the individual sample containers. WROC personnel interviewed said that after this information is gathered and provided to the SMO, WROC expects that the SMO will conduct all communications with the laboratories as LMITCO's representative for sample management, including any additional characterization information the laboratory may need for disposal of analysis wastes.

\section{Waste Reduction Operation Complex (WROC)}

This section is written to clarify the roles and responsibilities of the WROC personnel in ensuring proper characterization of wastes they receive and manage. Further clarification is contained herein explaining their roles associated with the management of waste they have received associated with TAN V-Tank wastes.

WROC management is responsible for nunning numerous waste storage and disposal facilities onSite, including but not limited to the MWSF and WERF. Since January 1997, WROC management was also assigned responsibility to operate two waste storage buildings at ICPP: ICPP 1617 and ICPP 1619. These ICPP facilities are interim status facilities under RCRA.

The WROC WGI personnel are the primary contacts for each waste generator to dispose of waste at any of the WO's facilities. WROC WGI personnel said that the procedures used to guide their activities are contained in WROC 3.1.6. A WGI noted that LMITCO procedure MCP-444 references the current Waste Analysis Plan (WAP), however, she stated the WAP is not a controlled document.

In regards to the TAN V-2 Tank oil separated and removed from the tank in 1982, WROC personnel interviewed stated that the oil has been stored at the MWSF as TSCA-regulated waste since 1986. This waste is tracked under WROC's tracking number WSID 1002 (reference description of this waste stream above). WROC generates a characterization identification number for a waste stream once it has a full profile and that number follows that stream to disposal. They continue to use that number for a single or multiple waste stream if it meets the waste profile.

The PCB-contaminated oil waste was recently repackaged and combined with other waste streams in preparation of WROC shipping this waste to the ORNL TSCA incinerator in Tennessee. This will be accomplished when the State of Tennessee lifts the moratorium on interstate shipments and treatment in Tennessee. A supervisor at WROC questions whether the oil/water separation technique used in the 1980s was an approved technique for managing that process. He also stated he believes the overall awareness of the TSCA regulations has increased in the last 5 years; he believes the current issues would not have been recognized 5 years ago.

In relation to the 1993 and 1996 sampling waste management, a WGI at WROC told the IRT members that she was assisting a subcontractor in characterizing waste in cargo containers shipped to them from TAN. The WGI said she suspected that waste from the 1993 TAN V-Tank sampling could be in the cargo containers. The WGI was the field team leader for the $1993 \mathrm{~V}$-Tank sampling event, and knew this would mean this waste was PCB contaminated. Based on this process knowledge information, the WROC staff contacted the ER ES\&H Compliance Officer and TANO personnel about the waste. When it was 
determined that the 1993 and 1996 sampling waste from the TAN V-Tank sampling activities was comingled with other TANO low-level radioactive waste in these containers, WROC rejected the waste. The 13 cargo containers were subsequently retumed to TAN from WROC. The cargo containers were placed in a CERCLA TAA at the RPSSA and marked as CERCLA investigation-derived waste (IDW) that contains PCB contamination.

WROC personnel interviewed during this review also expressed concerns with the characterization of waste shipped to them. They indicated that they believe there is a reluctance to fully characterize waste at the ICPP. The WROC personnel resolve characterization issues with the generators verbally. Several WGI personnel indicated ICPP has been trying to change waste codes after waste has been shipped from ICPP to WROC. In one case the waste had been burned in the WERF incinerator (reference WSID 1953 described above). In this case, WROC personnel knew that ICPP discovered typos in the waste code section of the forms submitted to WROC with the waste. They were not aware that the reason ICPP was trying to add " $F$ " listed codes to the waste, was that ICPP had recently been informed by the original generators of the waste, (ER), that F codes applied to V-Tank wastes. In another example provided by WROC, they felt waste sent to them recently by ICPP was not fully characterized, and have returned the waste to ICPP until they can feel the waste characterization is completed accurately (reference WSID 1971 described above). During interviews, the WROC personnel stated that ICPP gave them waste management issues to fix instead of fixing the issues themselves.

In reference to WROC's problems with the characterization of ICPP waste, they described for the IRT current practices as follows. WROC currently requires that a waste characterization form be completed by generators before shipping waste to them. This information is used to incorporate required information on the Uniform Hazardous Waste Manifest before transporting the waste. The current form, L-0435, Material and Waste Characterization Generator's Certification and Information, replaced the old 669 Forms. The old form was actually a two-part form. One part (669) was a profile that provided characterization data; the other (669A), was for container-specific information. The new forms were created to simplify the process, thus making it more cost-effective by permitting electronic versions of the forms. A WROC supervisor stated that the ICPP has another form, 5652, Request for Hazardous Material/Hazardous Waste Shipment Document Category II, for their internal use. Though this form is required by ICPP before generators at that facility ship any waste, the WROC supervisor stated that WROC does not want it, and they do not use it even when provided. The IRT noted that during the 1996 shipping incidents, had WROC used the forms provided by ICPP, some of the confusion would have been eliminated.

Though they do not participate with the WMAs at any of the INEEL facilities that currently have these processes in place, a WROC WGI expressed his concern with the process at ICPP. They indicated to the IRT that the new WMA Forms at TRA require numerous pages of information to be completed. It was this WGI's expressed opinion that once the WMA gives their approval, the generator still will have to do a 0435 Form per the Reusable Property and Recyclable Material Waste Acceptance Criteria (RRWAC), making the process more cumbersome. 


\section{Appendix A}

\section{Brief History of Evolution of the}

Department of Energy 


\section{Appendix A-1}

\section{BRIEF HISTORY OF EVOLUTION OF THE DEPARTMENT OF ENERGY}

In late 1945, Senator Brien McMahon (d-CT) introduced legislation that would create the Atomic Energy Commission (AEC). Although there was intense debate over the merits of military versus civilian control over nuclear research, Congress passed the McMahon bill and Truman signed it into law on 8/01/46. The McMahon Act, known officially as the Atomic Energy Act of 1946, transferred authority from the United States Army to the United States AEC. Comprised of a five-member civilian board serving full time, the new Commission was assisted by a general advisory committee and a military liaison committee.

The AEC's paramount objective remained ensuring the common defense and security. However, the Atomic Energy Act (AEA) charged the new Commission with directing the development and utilization of atomic energy toward improving the public welfare, increasing the standard of living, strengthening free competition in private enterprise, and promoting world peace.

Shortly after taking office, President Gerald Ford moved swiftly to establish a national energy board charged with developing a single national energy policy and program. On 10/08/74, he signed the Energy Reorganization Act of 1974, establishing the Energy Research and Development Administration (ERDA) and the Nuclear Regulatory Commission (NRC), which was given the licensing and regulatory functions of the now abolished AEC.

ERDA was created to achieve two goals: to focus the federal government's energy research and development activities within a unified agency whose major function would be to promote the speedy development of various energy technologies; and to separate nuclear licensing and regulatory functions from the development and production of nuclear power and weapons. ERDA was activated on 1/19/75.

The winter of 1976-1977 was bitterly cold. Natural gas supplies in the New England states fell critically short, forcing plants, businesses, and schools to close or curtail opening hours. As the nation shivered, people waited to see how the new president, Jimmy Carter, would deal with this new energy uncertainty.

On the day following his inauguration, President Carter announced that James R. Schlesinger would be his personal representative working with Congress to ease the natural gas shortage. Schlesinger, who had served as chairman of the AEC, Secretary of Defense, and director of the CIA, was soon recognized as Carter's new energy czar.

Schlesinger worked fast to carry out the President's energy policy and reorganization plans. In the first 90 days of Carter's presidency, Schlesinger's team developed the administration's basic energy reorganization plans and energy policy strategies. On 3/01/77, Carter presented Congress with his proposed energy reorganization legislation, which created the DOE.

Legislation creating the DOE passed the Senate on 5/18/77, and the House on 6/03/77. President Carter signed the bill into law (Public Law 95-91) on 8/04/77 creating the DOE with Schlesinger as the first Secretary of Energy. DOE was officially activated on 10/01/77. 


\section{Department of Energy Self-Regulation}

The AEC, ERDA, and DOE have regulated their activities through their own directives. The DOE and its predecessors were not regulated by other federal or state agencies until recently. The DOE is still exempt from regulation by agencies such as OSHA by specific notation in the implementing regulations. Historically, one federal agency never has authority over another federal agency. Further, a state has not had authority over any agency of the federal government.

This practice was challenged after the EPA promulgated a series of rules in the late $1970 \mathrm{~s}$. After several years of adversarial correspondence between various environmental and other public interest organizations and the DOE in the late 1970s and early 1980s, litigation was initiated in the federal district court for the eastern district of Tennessee by the Legal Environmental Assistance Foundation (LEAF) and other public interest organizations against the DOE. This litigation sought a determination that the RCRA regulations governing hazardous waste applied to such materials in the so-called Y-12 Plant at the ORNL (LEAF v. Hodel, 586 F. Supp. 1163, E.D. Tenn. 1984). The federal district court held in 1984 that the RCRA regulations applied to these hazardous wastes, including some mixed with radioactive constituents found in this defense facility. The DOE sought to avoid this extension of external regulatory authority, and immediately began preparations of proposed rulemaking to declare specifically that such "mixed" hazardous and radioactive wastes in the DOE complex were "byproduct material" as defined under the Atomic Energy Act (AEA), and thus specifically exempt from RCRA. The DOE issued its proposed mixed waste exemption rule in November 1985 (50 FR 45736, November 1985). This was not a unified federal front however; in July 1986, the EPA issued a formal determination that "wastes containing both hazardous waste and radioactive waste are subject to RCRA regulation" (51 FR 24504, July 1985). In formulating its approach, EPA took the difficult but explicit position that the hazardous component of a mixed waste stream was RCRA regulated but the radioactive component remained under the regulatory scope of the AEA, even where these hazardous and radioactive components were either essentially inextricable. The following year, DOE reluctantly agreed that its mixed radioactive and hazardous waste streams were subject to both RCRA and AEA regulation (52 FR 1593). For most practical purposes, however, because of the lead times involved in the development of RCRA program structures and state program delegation protocols for regulation of hazardous wastes by state regulators at federal facilities, RCRA. waste streams were virtually unregulated until 1989 or later. Subsequently, DOE successfully challenged the authority of state agencies to regulate and impose fines on federal facilities, relying on "vague:" language in RCRA that arguably did not waive the sovereign immunity of the federal enclaves in respect to such regulation. These successful challenges finally brought Congress back into the play, passing the Federal Facility Compliance Act (FFCA) in October 1992. Among other significant changes, the FFCA specifically amended RCRA so that EPA-delegated state hazardous waste regulatory agencies can, without further in dispute, permit, inspect, regulate, and impose civil fines at federal RCRA facilities, and investigate and prosecute RCRA criminal violations at federal facilities. Oddly, the mechanisms for federal agency (EPA) authority to permit, inspect, regulate, and sanction noncompliance at other federal agency (DOE) facilities remains convoluted and ineffective.

In short, clear delineation of RCRA regulation of mixed wastes at DOE facilities was only resolved at the federal statutory level in 1992, with the full implementation of comprehensive regulatory agency coverage, which is still in many ways in the consolidation phase. In contrast, the implementation of TSCA regulation of PCBs at DOE facilities, still exclusively under EPA authority, does not have even this clear a history, and the mechanisms for exercising that regulatory authority, especially the critical regulatory capacities to impose effective investigative and sanctioning processes under TSCA against DOE facilities, are by no means fully delineated, institutionally defined and funded, and broadly practiced even today. 
The DOE and its predecessors did not specifically regulate hazardous materials they used in their activities. These materials were usually an integral part of radioactive systems. It was generally accepted, that the controls on radioactive materials were sufficient to provide protection from or for the hazardous materials. The current DOE directives require contractors to follow the EPA regulations. The DOE considers itself fully regulated the same as private industry and requires its contractors to manage its facilities as such.

\section{INEEL OVERVIEW}

The INEEL, which employed more than 8,000 people at the end of 1996, is located on 890 square miles in the southeastern Idaho desert (Figure A-1). Other INEEL research and support facilities are located in Idaho Falls. Within the laboratory complex are nine major applied engineering, interim storage, and research and development facilities.

Established in 1949 as the National Reactor Testing Station (NRTS), for many years the INEEL was the site of the largest concentration of nuclear reactors in the world. Fifty-two reactors - most of them first-of-a-kind - were built, including the Navy's first prototype nuclear propulsion plant.

The Site is also a National Environmental Research Park, which is one of only seven in the nation. All land within the INEEL Site boundaries is a protected outdoor laboratory where scientists from DOE, other federal and state agencies, universities, and private research foundations conduct ecological studies.

\section{INEEL SITE ADMINISTRATION}

Management and operation of much of the INEEL is the responsibility of private contractors working under the direction of the U.S. Department of Energy, Idaho Operations Office. Lockheed Martin Idaho Technologies Company (LMITCO) is currently the prime contractor at the INEEL. Two other contractors at the site - the University of Chicago and Westinghouse Electric Corporation - report to DOE's Chicago Operations Office and the Pittsburgh Naval Reactor Office, respectively.

Argonne National Laboratory West (ANL-W) - ANL-W, part of Argonne National Laboratory operated by the University of Chicago, conducts research and development and operates facilities for DOE. Research is typically focused on areas of national concern including those relating to energy, nuclear safety, spent nuclear fuel treatment, nonproliferation, decommissioning and decontamination technologies, nuclear material dispositioning, and similar work.

Idaho Chemical Processing Plant (ICPP) - The ICPP houses facilities that provide safe interim storage for government-owned defense and research spent nuclear fuels. Other facilities at ICPP include a waste solidification facility and related waste storage bins, a state-of-the-art remote analytical laboratory, and a coal-fired steam generating plant. The ICPP's current emphasis is on developing new approaches and technologies to prepare spent fuel, high-level waste, and other nuclear materials for eventual disposal in a national repository.

Naval Reactors Facility (NRF) - NRF is the birthplace of the U.S. Nuclear Navy. Beginning in the early 1950 s, prototype reactors for both submarines and surface ships were developed and operated here. Until May 1995, when the last prototype was shut down, NRF served as a training school for officers and enlisted personnel destined for service aboard nuclear-powered ships. As it has for nearly 40 years, NRF continues to receive and examine Naval spent fuel. 


\begin{tabular}{|ll|}
\hline ANLW & Argonne National Laboratory - West \\
ARA & Auxiliary Reactor Area \\
CFA & Central Facility Area \\
CTF & Containment Test Facility \\
EBR I & Experimental Breeder Reactor I \\
EBR II & Experimental Breeder Reactor II \\
ICPP & Idaho Chemical Processing Plant \\
IET & Initial Engineering Test \\
NRF & Naval Reactor Facility \\
PBF & Power Burst Facility \\
RWMC & Radioactive Waste Management Complex \\
TAN & Test Area North \\
TRA & Test Reactor Area \\
TREAT & Transient Reactor Test (Facility) \\
TSF & Test Support Facility \\
WRRTF Water Reactor Research Test Facility \\
ZPPR & Zero Power Physics Reactor \\
\hline
\end{tabular}

\section{INEL Boundary}

Roads

Towns

- Facilities
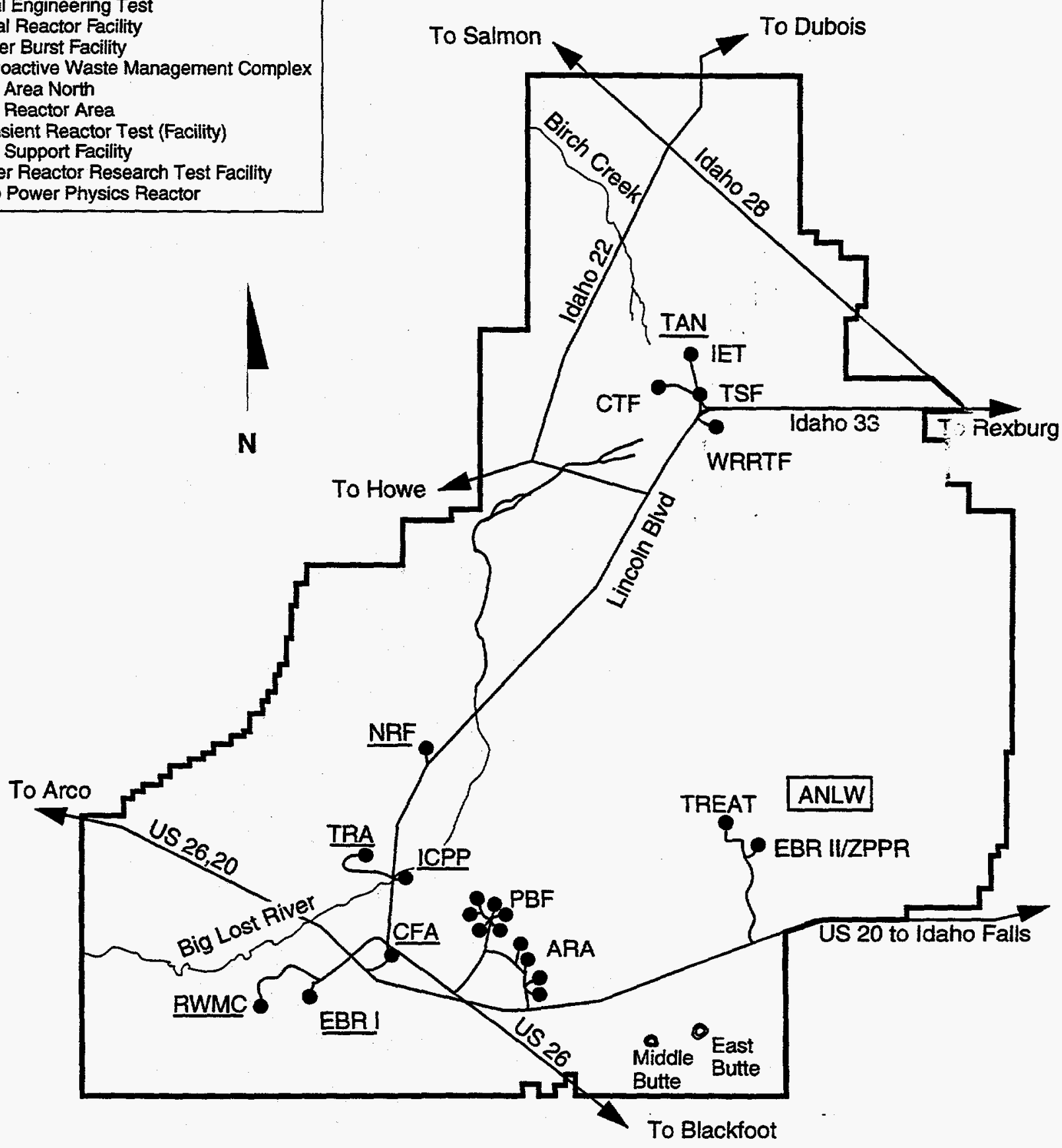

Figure A-1. Map of the INEEL. 
Waste Reduction Operations Complex (WROC) - WROC is housed in an area formerly used for reactor operations. The complex consists of the Waste Engineering Development Facility, the MWSF, and the WERF. The WROC facilities provide for the safe treatment, storage, and recycling of the INEEL's radioactive, mixed, and industrial/commercial wastes.

Radioactive Waste Management Complex (RWMC) - Various strategies for waste storage, processing, and disposal are studied at RWMC, which was established in 1952 as a controlled area for disposal of solid radioactive wastes generated in INEEL operations. From 1954 until 1988, the facility received defense wastes for storage. Today the RWMC receives radioactive, mixed transuranic, and low-level waste, which is primarily generated at the INEEL. The Stored Waste Examination Pilot Plant (SWEPP), a state-of-the-art waste examination/certification facility, is housed at RWMC. Currently, SWEPP is used for certifying waste for shipment to a permanent repository.

Test Area North (TAN) - TAN, located at the northern end of the INEEL Site, consists of facilities for handling, storage, examination, and research of spent nuclear fuel. TAN also houses a project to manufacture armor packages for Army tanks.

In Town Facilities - In town facilities include various laboratories that conduct various types of research in support of DOE missions.

Test Reactor Area (TRA) - TRA, the world's most sophisticated materials testing complex, houses extensive facilities for studying the effects of radiation on materials, fuels and equipment. The Advanced Test Reactor (ATR), located at TRA, produces a neutron flux that allows simulation of long-duration radiation effects on materials and fuels. ATR is also used for production of important isotopes used in medicine, research, and industry.

\section{Some History of the INEEL}

In the late 1940s, interest was building to develop a breeder reactor. Scientists Walter Zinn and Leo Szilard demonstrated in an experiment in 1939 that a chain reaction could be achieved. Zinn later joined Szilard and Enrico Fermi, who achieved a nuclear chain reaction at the University of Chicago in 1942.

Zinn wanted to build a test reactor near Chicago, but the AEC's advisory committee on safety, headed by physicist Edward Teller, disagreed. Teller said, in a 1987 Post Register interview, "We did not want to have people who had nothing to do with it to come closer than 5 miles to a reactor."

So thus began a search for the best place to have a national reactor testing station. After 9 months of studying 74 prospective sites, the AEC selected the Arco desert west of Idaho Falls as being just what was needed. They announced the choice on $3 / 22 / 49$, thus beginning the NRTS.

In August 1974, the NRTS was renamed the Idaho National Engineering Laboratory (INEL) to emphasize the engineering expertise of the laboratory and that it was involved in much more than nuclear reactors. In response to the changing roles and missions of the site, the name was recently changed to the Idaho National Engineering and Environmental Laboratory (INEEL). Prime operating contractors, operating most of the INEEL [other than ANL-W, ICPP, (some of the time) and the Naval Reactor Facilities, operated by Westinghouse] are:

- $\quad$ Phillips Petroleum Company, 1953-67 
- Idaho Nuclear Company, 1967-72

- $\quad$ Aerojet Nuclear Company, 1972-76

- EG\&G Idaho Company, 1976-94

- Lockheed Martin Idaho Technologies Company (originally Lockheed Idaho Technologies Company) 1994-present.

The prime contractors have always operated most of the facilities at the INEEL and also the support services for the site.

One of the major facilities at the INEEL is the ICPP. These contractors operated that facility:

- American Cyanamid, 1950-53

- Phillips Petroleum Company, 1953-67

- Idaho Nuclear Company, 1967-72

- $\quad$ Allied Chemical Company, 1972-79

- Exxon Nuclear Idaho Company, 1979-84

- Westinghouse Idaho Nuclear Company, 1984-94

- Lockheed Martin Idaho Technologies Company, 1994-present.

One INEEL area that has a very interesting history is TAN. Feasibility studies for an atomic powered airplane began in 1946. From this, developed the Air Force's Aircraft Nuclear Propulsion (ANP) program. General Electric Corporation was selected to build the nuclear engine for the aircraft. A number of such engines were developed at TAN. Also built at TAN was a large hangar to house the aircraft once it was built. Many of the TAN facilities including the TAN Hot Shop were built in support of this program. As part of the associated facilities with the Hot Shop, there was a liquid waste system installed including the V-Tanks discussed in this report.

The ANP program was plagued by a lack of direction and frequent changes in emphasis and direction by both the Air Force and the Department of Defense. On March 28, 1961, President John F. Kennedy issued a statement canceling the ANP program. The airplane that was never built had cost an estimated \$1.04 Billion. An interview with an old time employee at TAN stated General Electric, the ANP contractor, just walked away from the facility.

The Loss-of-Fluid-Test (LOFT) reactor was also a part of TAN. This facility included the LOFT Containment and Service Building (reactor facility), and aircraft hangar from the defunct ANP program, the LOFT Reactor Control and Equipment Building, and numerous support facilities. LOFT, constructed from 1965 to 1975 , was a scaled down version of a commercial plant. LOFT was the only nuclear reactor in the world that could repeatedly simulate different kinds of loss-of-coolant accidents that might occur in commercial power plants. The final test, conducted on $7 / 09 / 85$, was the most significant severe fuel damage test ever conducted in a nuclear reactor. The test purposely melted the core and was the $38^{\text {th }}$ experiment conducted in the facility. The fuel was removed, however most of the facility remains as left. 
As can be seen from the foregoing information, the INEEL has gone through many changes in roles and missions. It has been under the auspices of the AEC, ERDA, and the DOE. It has changed operating contractors many times with a corresponding change in management and operating direction. And finally there have been many changes of personnel during the almost 50 years since the NRTS was first conceived.

The INEEL has accomplished much during this time. However, as someone once said, "Change is the mother of twins, Progress and Trouble." This holds true at the "Site." Along with the progress, there have been problems created along the way as goals and direction changed with time. This report deals with some of those problems and the evolving of environmental concerns with time. The story associated with this review sometimes is somewhat fragmented since it is difficult to reconstruct all of it over a long period of time amid all of the changes. The physical conditions have changed along with the people and the paperwork. 